\title{
Otimização multiobjetivo das dimensões dos ambientes de uma residência unifamiliar baseada em simulação energética e estrutural
}

\author{
Multi-objective optimization of the dimensions of a \\ $d$ welling building based in energy and structure \\ simulation
}

\begin{abstract}
Ligiana Pricila Guimarães Fonseca
Vitor Dias Lopes Nunes

Laila Oliveira Santana

Joyce Correna Carlo

Kléos Magalhães Lenz César Júnior

Resumo

Ligiana Pricila Guimarães

Fonseca

Universidade Federal de Viçosa Viçosa - MG - Brasil

Vitor Dias Lopes Nunes Universidade Federal de Viçosa Viçosa - MG - Brasil

Laila Oliveira Santana Universidade Federal de Viçosa Viçosa - MG - Brasil

Joyce Correna Carlo

Universidade Federal de Viçosa Viçosa - MG - Brasil

Kléos Magalhães Lenz César

Júnior

Universidade Federal de Viçosa Viçosa - MG - Brasil

Recebido em 23/03/16 Aceito em 05/09/16

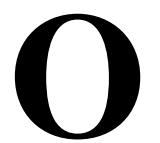

desenvolvimento da tecnologia computacional nas últimas décadas levou a otimização associada à parametrização a possibilitar o desenvolvimento de projetos de melhor desempenho, com ou sem integração com a simulação. $\mathrm{O}$ intuito deste trabalho foi aplicar a otimização baseada em simulação na forma de uma edificação residencial unifamiliar com o objetivo de encontrar a composição que apresentasse o melhor desempenho térmico com o menor custo dos materiais construtivos, considerandose restrições estruturais. Foram utilizados os programas Rhinoceros e Energy Plus, além de plug-ins para modelagem paramétrica, o intercâmbio de informações entre os programas e a condução da otimização. Foram realizadas duas simulações, a primeira considerando os custos dos componentes construtivos e os graus-hora de aquecimento e resfriamento combinados e a segunda considerando os custos e graus-hora de aquecimento, que produziu resultados mais relevantes. Dois casos de cada solução de Pareto foram selecionados para análise, dentre 19,8 mil e 27,4 mil casos obtidos com uso de algoritmos evolucionários. Apesar das limitações de algumas das ferramentas, foi verificado um grande potencial de aplicação deste método no desenvolvimento de projetos arquitetônicos.

Palavras-chaves: Otimização multiobjetivo baseada em simulação. Modelagem paramétrica. Desempenho térmico. Restrições estruturais. Edificação residencial.

\section{Abstract}

The development of computer technology in the past few decades led optimization associated with parameterization to develop designs that perform better, with or without the use of computer simulation. The purpose of this study was to apply this method to optimize the shape of a single family residential building with the goal of finding the design that presented the best thermal performance with the lowest cost of construction materials, considering structural constraints. The software Rhinoceros, Energy Plus and plug-ins for parametric modelling, information exchange between software and conduction of optimization were used in this study. Two simulations were performed, one considering the cost of construction materials and combined heating and cooling degree-hours, the second considering cost and heating degree-hour, which produced more relevant results. Two cases of each Pareto Front were selected for analysis, out of 19.8 thousand and 27.4 thousand cases obtained through evolutionary algorithms. Despite the limitations presented by some tools, the study demonstrated that there is great potential for implementation of this technology in the development of architectural projects.

Keywords: Multi-objective optimization-based simulation. Parametric modelling. Thermal performance. Structural restrictions. Residential building.
\end{abstract}

FONSECA, L. P. G.; NUNES, V. D. L.; SANTANA, L. O.; CARLO, J. C.; CÉSAR JÚNIOR, K. M. L. Otimização multiobjetivo 267 das dimensões dos ambientes de uma residência unifamiliar baseada em simulação energética e estrutural. Ambiente Construído, Porto Alegre, v. 17, n. 1, p. 267-288, jan./mar. 2017. ISSN 1678-8621 Associação Nacional de Tecnologia do Ambiente Construído. http://dx.doi.org/10.1590/s1678-86212017000100135 


\section{Introdução}

A modelagem paramétrica da forma na arquitetura tem possibilitado o desenvolvimento de formas complexas ao permitir a construção de dependências entre componentes construtivos, a criação de regras/restrições e de relações entre os elementos (FLORIO, 2011). Há uma tendência de crescimento do uso de programas de modelagem paramétrica, que tem sido absorvida de forma rápida no campo da arquitetura em alguns países, porém com resistência em outros ${ }^{1}$. A modelagem paramétrica auxilia a concepção e, por conseguinte, o processo criativo, (FLORIO, 2011) por permitir uma infinidade de soluções projetuais de forma rápida. Ao final da etapa de concepção, a solução final pode ser definida tendo como critério de julgamento o atendimento a intenções ou objetivos estabelecidos pelas partes interessadas no projeto.

Apesar de apresentar diversas vantagens em relação aos softwares de modelagem convencionais, os softwares de modelagem paramétrica não têm sido absorvidos de forma rápida no campo da engenharia civil e da arquitetura em alguns locais (ARO; AMORIM, 2004). Por outro lado, a necessidade de criação de projetos mais sustentáveis ambientalmente, que tenham menor impacto ambiental e melhor conforto térmico com reduzido consumo de energia, incentivou a disseminação de uma das correntes de design do século XXI, chamada projeto baseado em desempenho. Segundo Shi e Yang (2013), diferentemente da metodologia convencional, que possui seu foco no desenho do espaço e da forma, o projeto baseado em desempenho tem seu foco no desempenho ecológico e ambiental de edificações, sem deixar de considerar a estética. Na metodologia convencional de projeto, muitos programas utilizados para modelagem da forma não permitem entrada de informações para avaliação do desempenho da edificação, e o simulador insere esses dados posteriormente ao desenho final do projeto no programa para avaliação do desempenho (SHI; YANG, 2013). Se, ao final da simulação, o projeto não atingiu o desempenho desejado, sua remodelação pode ocasionar um esforço indesejado ao processo. $\mathrm{O}$ projeto arquitetônico baseado em desempenho apresenta-

${ }^{1}$ No Brasil, a utilização de ferramentas paramétricas é recente (DOMINGOS, 2002; FLORIO, 2009, 2011; VASCONCELOS; BORDA; VECCHIA, 2014). Andrade e Ruschel (2009) identificaram que publicações na área têm surgido há pouco mais de uma década em congressos e eventos nacionais. Santana, Guimarães e Carlo (2015) identificou que, apesar de a parametrização ser aplicada a estudos de eficiência energética há quase duas décadas no Brasil, a avaliação que incluiu parâmetros da forma é recente e devida aos avanços computacionais. se, portanto, como uma abordagem eficaz para a concepção de desenhos mais eficientes, desde que os entraves referentes à interoperabilidade sejam superados, o que tem ocorrido na última década (ATTIA et al., 2012).

Associado à parametrização e ao conceito de projeto baseado em desempenho, a otimização baseada em simulação (OBS) é uma estratégia para concepção de projetos que atendam mais adequadamente a um objetivo específico. Otimizar, segundo Nyguyen et al. (2014), está relacionado ao processo de busca por soluções mais próximas a um ponto ótimo, que atendam de forma mais efetiva a um objetivo. No entanto, a otimização de edificações permanece uma ciência complexa, pois envolve um grande número de variáveis, equações não lineares e longos tempos de simulação (LARTIGUE; LASTERNAS; LOFTNESS, 2014).

A simulação computacional para solução de problemas complexos de sistemas de engenharia tem sido largamente utilizada nos últimos anos (NGUYEN et al., 2014), sendo a simulação termoenergética um meio promissor para o projeto de edificações com melhor conforto térmico, menor consumo de energia e menor impacto ambiental. Segundo Gossard et al. (2013), a melhoria do desempenho térmico de uma edificação pode ser atingida através de duas abordagens: tentativa e erro; ou com algoritmos de otimização. Embora o método de tentativa e erro possa gerar soluções aceitáveis, a otimização dá maiores chances de indicar as melhores soluções para um projeto baseado no(s) objetivo(s) desejado(s) (MAGNIER; HAGHIGHAT, 2009).

Um dos métodos utilizados para o projeto de edificações de melhor desempenho é a simulação paramétrica, que consiste em promover mudanças em uma das variáveis de projeto enquanto todas as outras são mantidas constantes, para avaliação do efeito desta no desempenho da edificação (NGUYEN et al., 2014). No entanto, esse método não é interativo, o que pode omitir a descoberta de soluções ótimas de projeto. Uma vez que a interação entre variáveis pode conduzir a diferentes soluções de projeto e que essa interação apresenta soluções de desempenho não lineares, a otimização baseada em simulação pode ser o caminho para alcançar projetos de edificações de melhor desempenho. De acordo com Nguyen et al. (2014), a otimização baseada em simulação, ou otimização numérica, tem sido aplicada desde os anos 1980 em escala internacional, em função de avanços na tecnologia computacional. No entanto, apenas a partir da segunda metade dos anos 2000 
verifica-se um aumento crescente no interesse por estudos na área de otimização de edificações (Figura 1).

No caso do Brasil as publicações são também recentes, como Silva e Ghisi (2013), que utilizaram a simulação numérica para realizar uma análise de sensibilidade dos parâmetros termofísicos de uma edificação residencial seguindo o método de simulação dos Requisitos Técnicos da Qualidade para o Nível de Eficiência Energética de Edificações Residenciais (RTQ-R). Santana, Guimarães e Carlo (2015) desenvolveram uma análise de sensibilidade de parâmetros da forma utilizando as equações para determinação do desempenho de edificações residenciais para verão e inverno (do RTQ-R) para a Zona Bioclimática 3, porém o processo não envolveu simulação.

Segundo Nguyen, Reiter e Rigo (2014), a otimização pode ser classificada de acordo com o número de funções objetivo. Ela pode ser uma otimização mono ou multiobjetivo. Apesar de a primeira ser mais comum², a otimização multiobjectivos e aproxima mais de problemas reais, pois projetistas geralmente necessitam lidar com critérios de projeto conflituosos (NGUYEN; REITER; RIGO, 2014). A otimização multiobjetivo ou otimização de Pareto (NGUYEN; REITER; RIGO, 2014), utiliza dois ou mais objetivos, e, com base em uma análise visual e nos valores de cada solução referentes aos objetivos, o projetista tem a liberdade de escolher uma ou mais soluções que se apresentem interessantes a seu projeto.

Segundo Evins (2013), os algoritmos evolucionários estão entre os mais comuns aplicados em otimização. Eles são baseados na teoria da evolução de Darwin, em que são criadas populações de soluções, denominadas indivíduos, e cada um destes é avaliado conforme seu desempenho perante os objetivos propostos. A cada geração criada, os indivíduos de pior desempenho são eliminados da população (EVINS, 2013), enquanto os melhores são mantidos para o processo de criação e seleção da próxima geração. Conceitos de cruzamento (trocas de elementos entre dois indivíduos para geração de um novo) e mutação genética (alterações aleatórias) são aplicados entre os algoritmos evolucionários (EVINS, 2013). Segundo Nguyen; Reiter e Rigo (2014), os algoritmos genéticos estão entre os mais populares nas comunidades que trabalham com simulação de desempenho de edificações, pois são capazes de lidar com variáveis contínuas e discretas, são eficientes em otimizações multiobjetivo, são menos prováveis de se prender a soluções locais mínimas ${ }^{3}$ e possuem melhor habilidade de lidar com descontinuidades, problemas multimodais e problemas altamente restritivos $^{4}$ sem se prender a soluções locais mínimas (COLORNI; DORIGO; MANIEZZO, 1990).

\section{Figura 1 - Tendência de crescimento do número de estudos de otimização na ciência de edificações em nível internacional}

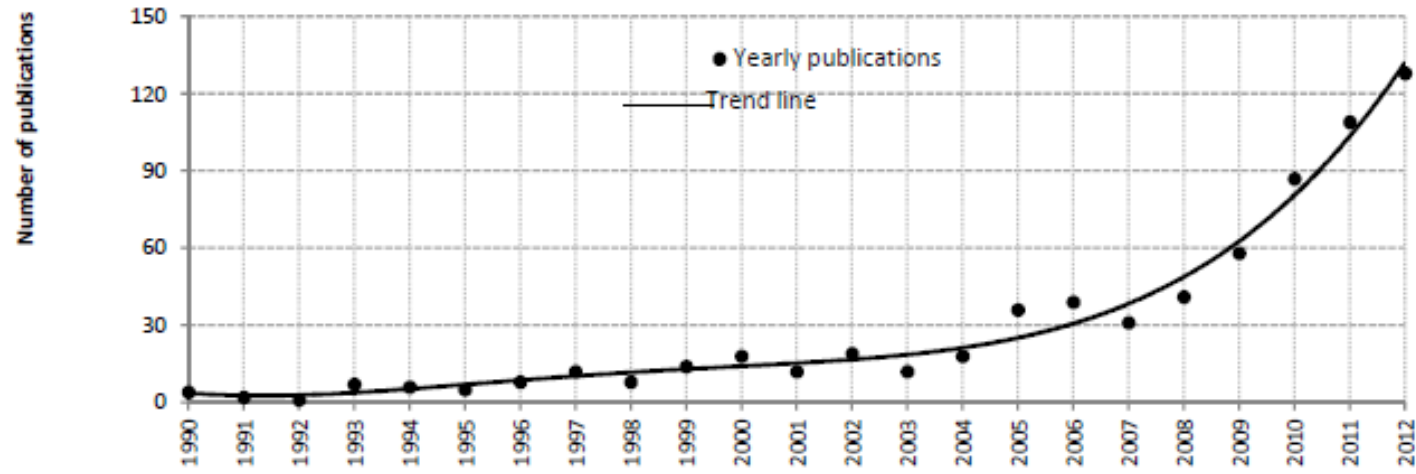

Fonte: Nguyen, Reiter e Rigo (2014).

\footnotetext{
${ }^{2}$ Nguyen, Reiter e Rigo (2014) identificou que 60\% dos estudos de otimização de edificações apresentavam apenas uma função objetivo. ${ }^{3}$ No processo de otimização, o campo de busca das próximas soluções pode se tornar restrito a pequenos espaços, ignorando o universo de possibilidades representado pela dispersão dos resultados cujas dimensões são os (eixos compostos pelos) objetivos. São chamadas Local minimum solutions, e podem comprometer a otimização caso a busca se restrinja a esses espaços.

${ }^{4}$ Problemas altamente restritivos (highly constrained problems) são problemas de otimização em que uma alteração mínima a uma solução viável pode gerar uma solução inviável (COLORNI; DORIGO; MANIEZZO, 1990).
} 
Um dos problemas apresentados aos que trabalham com otimização baseada em simulação (OBS) é o critério de parada a ser definido. Autores têm desenvolvido ferramentas que possibilitam ao usuário escolher o critério de parada para seu processo de otimização. $\mathrm{O}$ plug-in para Grasshopper/Rhinoceros Goat, desenvolvido para otimização mono-objetiva, possibilita ao usuário interromper o processo de otimização após um intervalo de tempo predefinido quando o valor da função objetivo obtida pelas novas soluções não apresenta mais grandes variações (convergência), quando os parâmetros não apresentam grandes diferenças entre as soluções mais novas e "adaptadas" (convergência), ou a partir de um valor do objetivo estipulado pelo usuário.

Um plug-in desenvolvido para o Grasshopper que é interessante para a condução de otimizações multiobjetivo é o Octopus, criado com base em princípios evolucionários (FOOD4RHINO, 2016). Ele possibilita ao usuário trabalhar com dois ou mais objetivos, como a diversidade de parâmetros, o que aumenta as chances de que o algoritmo explore todo o campo de busca de soluções. O Octopus possibilita utilizar dois algoritmos genéticos na otimização: $\mathrm{HypE}^{5}$ ou SPEA-2 ${ }^{6}$. Ele possibilita também determinar o tamanho da população que será criada a cada geração, e como critério de parada o usuário pode estabelecer um número máximo de gerações. Além desse critério, o usuário pode ainda utilizar a convergência de soluções: ele pode se orientar por meio de um gráfico em que o intervalo dos parâmetros utilizados são plotados. Cada solução se apresenta como uma linha conectando os parâmetros; quanto mais próximas as linhas, mais o projeto se aproxima da convergência (Figura 2).

Além disso, o Octopus permite ao usuário escolher visualmente uma solução para análise dos parâmetros e dos indicadores de desempenho. Sua relevância como motor de otimização para o Grasshopper é também por evitar que a otimização seja interrompida ao se deparar com casos impossíveis de se chegar a uma solução viável. Ele "salta" o caso se um tempo máximo de avaliação de cada simulação for determinado pelo usuário.

Plug-ins que conectam o Grasshopper a programas de simulação têm sido criados para interoperabilizar o processo de otimização. O Archsim, que integra o Grasshopper ao Energy Plus, possibilita a realização de simulações dinâmicas e traz para o ambiente de modelagem da forma o processo de entrada de dados necessários à simulação. Diversos resultados de simulações podem ser extraídos do Archsim para o Grasshopper, de acordo com as potencialidades do EnergyPlus e com os próprios recursos desse plugin, tais como modelo de rede para ventilação natural, simulação de um ar condicionado ideal e índices de conforto térmico segundo a Standard 55 (AMERICAN..., 2010).Todos os plug-ins citados encontram-se em fase de desenvolvimento ou aperfeiçoamento, apresentando algumas limitações, porém se percebe uma tendência crescente em relação a seu uso por pessoas que trabalham com simulação e otimização de espaços construídos.

\section{Figura 2 - Gráfico de convergência do caso inicial (a) e do mesmo após 106 gerações (b), cada qual com uma população de 100 indivíduos}

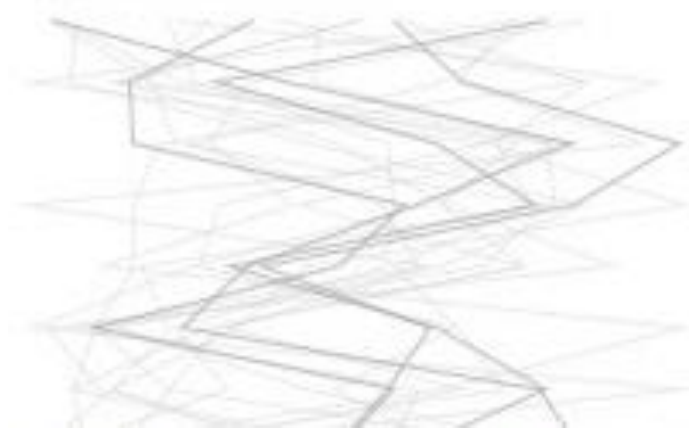

(a)

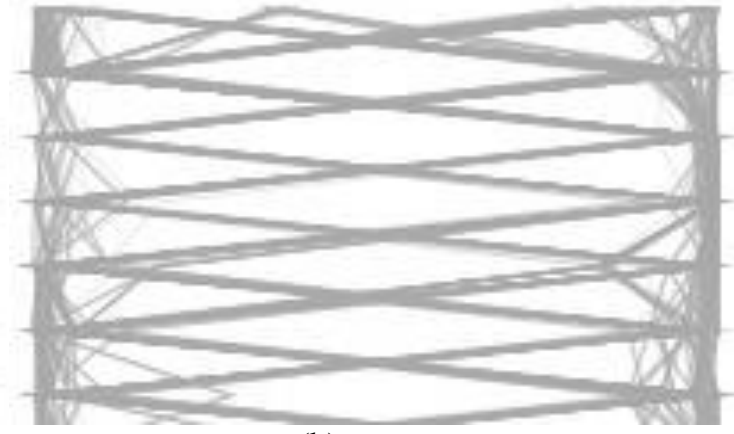

(b)

\footnotetext{
${ }^{5} \mathrm{HypE}$ é um algoritmo de estimativa de hipervolume criado pelos autores aqui citados para otimização multiobjetivo em quatro dimensões. Ele é baseado na amostragem de Monte Carlo e seu desempenho foi comparado com três outros algoritmos evolucionários multiobjectivo: NSGA-II, SPEA-2 e IBEA, que não otimizam hipervolume. 0 algoritmo foi considerado como altamente competitivo comparado aos outros (BADER; ZITZLER, 2008).

${ }^{6}$ O SPEA-2 é um algoritmo evolucionário multiobjetivo elitista criado pelos autores aqui citados que apresenta evoluções em relação a seu algoritmo predecessor, SPEA. Ele foi testado com relação ao seu predecessor e dois outros algoritmos genéticos populares baseados em métodos elitistas (PESA e NSGA-II) e apresentou resultados promissores (ZITZLER; LAUMANNS; THIELE, 2001).
} 
O objetivo deste trabalho é identificar o potencial de otimização das dimensões dos ambientes regularmente ocupados de uma edificação residencial unifamiliar usando funções objetivo de desempenho térmico e de custos, considerando-se restrições estruturais na parametrização da forma.

\section{Materiais e métodos}

Um modelo de edificação residencial foi criado no Rhinoceros 5.0 através do Grasshopper 0.9.0076, e parâmetros foram estabelecidos para a otimização das dimensões dos ambientes. O Archsim 1.4.0.1 foi utilizado como ferramenta interoperável entre o Rhino/Grasshopper e o Energy Plus 8.2.0 em uma simulação para o clima de Viçosa, $\mathrm{MG}^{7}$. Foram conduzidas duas otimizações. Na primeira, dois objetivos foram estabelecidos. O primeiro era encontrar o caso que apresente tanto o melhor desempenho térmico para verão e inverno quanto o menor custo dos materiais. Em função dos resultados obtidos na primeira otimização, a segunda foi conduzida para encontrar o caso de melhor desempenho térmico para inverno e o menor custo dos materiais construtivos. Uma restrição estrutural foi estabelecida em relação ao dimensionamento das lajes, que seriam alteradas na otimização, o que possibilitaria a exclusão de casos que seriam impossíveis estruturalmente. É importante destacar que o modelo térmico criado é naturalmente condicionado, com uso do módulo Airflow Network do Energy Plus, pois esse modo de condicionamento é predominante nas residências brasileiras, razão pela qual os custos da energia não foram contabilizados. Isso implicou uma função multiobjetivo cujos custos são geridos por equações no Grasshopper, enquanto o desempenho térmico é gerido pelo Archsim. Dessa maneira, os custos de consumo energético não fizeram parte do modelo de custos da edificação.

\section{Modelo da unidade habitacional}

O modelo de habitação criado para o projeto consistiu em uma edificação de dois pavimentos com quatro dormitórios, uma sala, um escritório, uma cozinha e um banheiro, sendo dois dormitórios localizados no primeiro pavimento, e os demais ambientes, térreos. O modelo com base em Santana, Guimarães e Carlo (2015) (Figura 3), que se apoiou em Sorgato (2011), porém com o acréscimo de um segundo pavimento.

Devido ao fato de a otimização ser dispendiosa em relação ao tempo computacional, o modelo de Santana, Guimarães e Carlo (2015) foi

"Viçosa, MG, latitude $20^{\circ} 45^{\prime} 14^{\prime}$ 'S, longitude $42^{\circ} 52^{\prime} 54^{\prime \prime} \mathrm{O}$, altitude $649 \mathrm{~m}$; Zona Bioclimática 3. simplificado. Todos os ambientes, exceto a circulação entre a sala, o escritório e o quarto, foram modelados como zonas térmicas para simulação no Energy Plus, porém apenas os ambientes de permanência prolongada foram considerados na otimização. Além disso, o vão da escada entre o térreo e o primeiro pavimento não foi modelado devido a limitações de modelagem do plugin que não modela o efeito chaminé entre esses pavimentos. $\mathrm{O}$ número de variáveis também foi reduzido para agilizar o processo de convergência de soluções: as dimensões dos ambientes variaram a partir da origem nos eixos das ordenadas e abscissas (Figura 4).

As aberturas para ventilação e iluminação dos ambientes foram modeladas segundo o mínimo estabelecido pelo Regulamento Técnico da Qualidade para o Nível de Eficiência Energética de Edificações Residenciais (RTQ-R) (INSTITUTO..., 2012) e o Código de Obras de Viçosa (PREFEITURA..., 2015). Como este último era mais exigente, predominou no dimensionamento das aberturas. A área de aberturas foi determinada pela relação de $1 / 6$ da área do piso para os ambientes de permanência prolongada e de $1 / 8$ para a cozinha, o banheiro e a circulação, sendo $45 \%$ das aberturas destinados à ventilação (5\% corresponderiam aos caixilhos).

As aberturas para ventilação e iluminação dos ambientes foram modeladas segundo o mínimo estabelecido pelo Regulamento Técnico da Qualidade para o Nível de Eficiência Energética de Edificações Residenciais (RTQ-R) (INSTITUTO..., 2012) e o Código de Obras de Viçosa (VIÇOSA, 2015). Como este último era mais exigente, predominou no dimensionamento das aberturas. A área de aberturas foi determinada pela relação de $1 / 6$ da área do piso para os ambientes de permanência prolongada e de $1 / 8$ para a cozinha, o banheiro e a circulação, sendo $45 \%$ das aberturas destinados à ventilação $(5 \%$ corresponderiam aos caixilhos).

A cobertura da sala e do escritório foi estabelecida como um terraço verde, modelado como um componente composto dos materiais descritos na Tabela 1, desconsiderando os efeitos de evapotranspiração ${ }^{8}$. Os dormitórios 3 e 4 e a circulação tiveram uma cobertura ventilada com telha cerâmica, que foi modelada como uma zona térmica.

Os materiais componentes das camadas de vedação da envoltória foram determinados a partir da NBR 15220 (ABNT, 2003), de Ordenes et al. (2003) e

${ }^{8} \mathrm{O}$ Archsim não permite usar o recurso de modelagem de coberturas verdes, apesar de essa ser uma possibilidade do Energy Plus. 
de Sorgato (2011). Os materiais modelados são apresentados na Tabela 1. Alguns componentes foram simplificados, conforme recomendado por Ordenes et al. (2003). Deve-se ressaltar que as características da edificação - inclusive os materiais - foram determinadas entre aquelas que satisfazem um elevado desempenho térmico, a fim de isolar as variáveis de interesse ${ }^{9}$ (SANTANA $e$ al., 2015) e que neste artigo são aquelas relativas às dimensões dos ambientes.

Figura 3 - Modelo de edificação proposta por Santana, Guimarães e Carlo (2015)

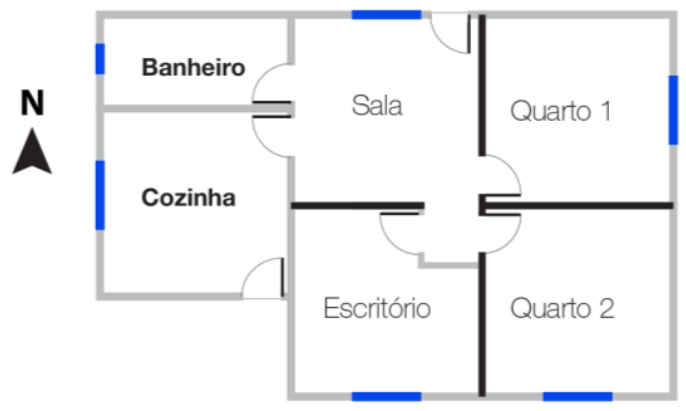

Figura 4 - Modelo de edificação utilizado - Modelo real planejado e modelo esquemático desenhado no Grasshopper

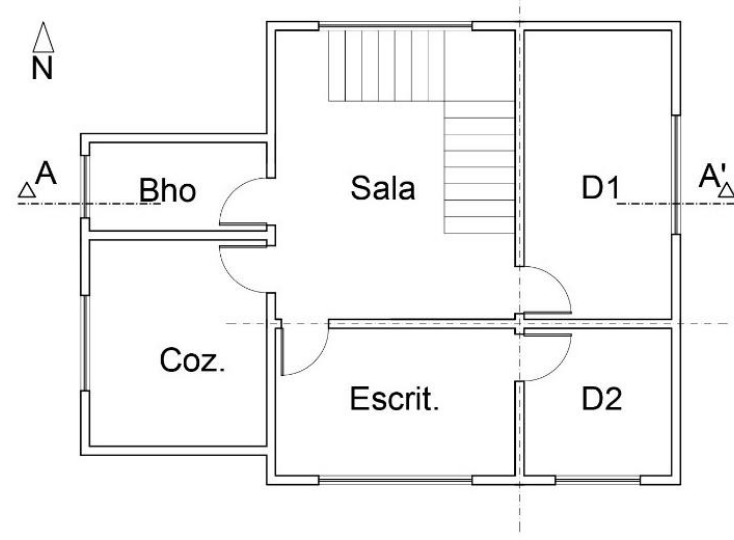

Planta Baixa Térreo

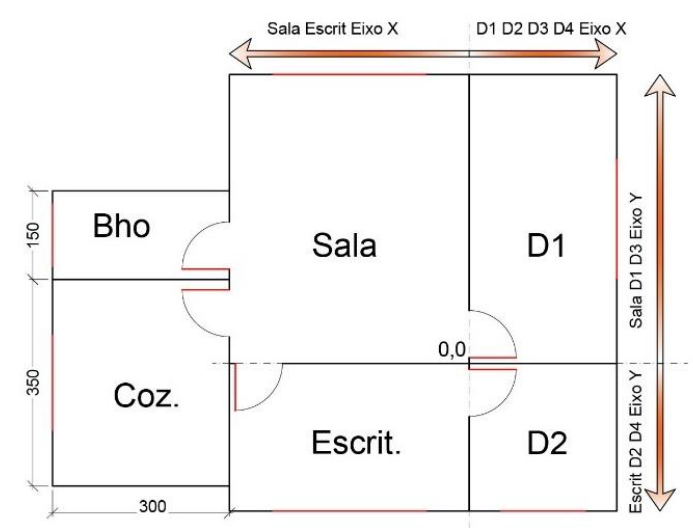

Planta Baixa Esquemática Térreo

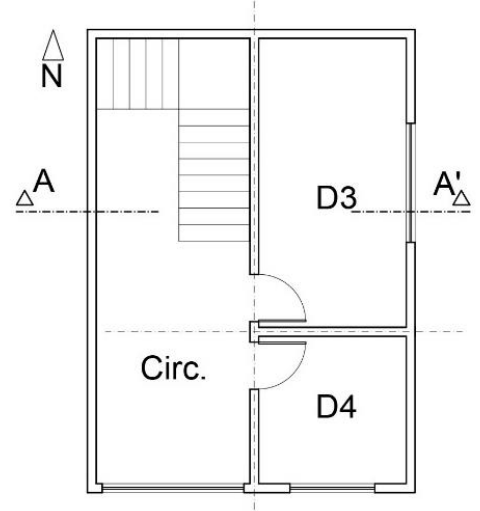

Planta Baixa 1 Pav.

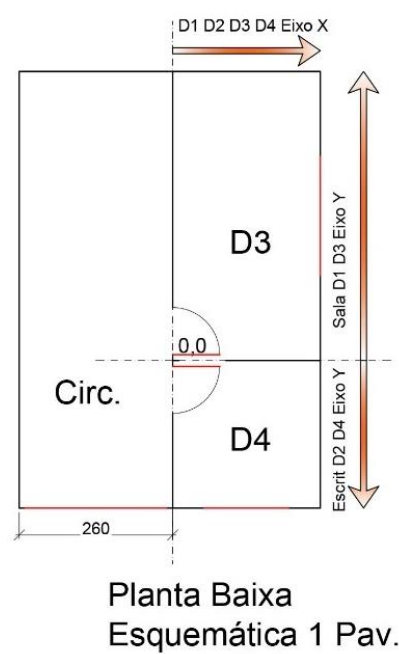

${ }^{9}$ Foram determinados materiais que satisfaziam aos pré-requisitos para absortância solar, transmitância térmica e capacidade térmica das paredes e coberturas do RTQ-R (INSTITUTO..., 2012) para nível A. 
Tabela1 - Materiais componentes dos elementos de vedação da residência

\begin{tabular}{|c|c|c|c|c|}
\hline Componente & Materiais & $\begin{array}{c}\text { Espessura } \\
\text { real }(\mathrm{cm})\end{array}$ & $\begin{array}{c}\text { Espessura } \\
\text { eq. }(\mathbf{c m})\end{array}$ & Considerações otimização \\
\hline \multirow{11}{*}{ Paredes } & $\begin{array}{l}\text { Pintura cor branco- } \\
\text { fosco (absortância } \\
36,7 \% \text { ) }\end{array}$ & & 0 & $\begin{array}{l}\text { A absortância da tinta foi usada } \\
\text { como absortância do revestimento } \\
\text { externo na otimização. }\end{array}$ \\
\hline & Argamassa de reboco & 0,5 & 0 & $\begin{array}{l}\text { Desconsiderado na otimização. } \\
\text { Apenas nos custos. }\end{array}$ \\
\hline & $\begin{array}{l}\text { Argamassa de } \\
\text { emboço }\end{array}$ & 2,0 & 2,5 & $\begin{array}{l}\text { Considerado um emboço de } 2,5 \\
\mathrm{~cm} \text { na otimização, conforme } \\
\text { indicado por Ordenes et al. }\end{array}$ \\
\hline & Chapisco & 0,5 & 0 & $\begin{array}{l}\text { Desconsiderado na otimização. } \\
\text { Apenas nos custos. }\end{array}$ \\
\hline & Ceram Tij. 8 fur quad & \multirow{3}{*}{19} & 1,4 & \multirow{3}{*}{$\begin{array}{l}\text { Modeladas as camadas de } \\
\text { composição do bloco cerâmico } \\
\text { para otimização. }\end{array}$} \\
\hline & Câmara de ar & & 3,0 & \\
\hline & Ceram Tij. 8 fur quad & & 1,4 & \\
\hline & Chapisco & 0,5 & 0 & $\begin{array}{l}\text { Desconsiderado na otimização. } \\
\text { Apenas nos custos. }\end{array}$ \\
\hline & $\begin{array}{l}\text { Argamassa de } \\
\text { emboço }\end{array}$ & 2,0 & 2,5 & $\begin{array}{l}\text { Considerado um emboço de } 2,5 \\
\mathrm{~cm} \text { na otimização, conforme } \\
\text { indicado por Ordenes et al. }\end{array}$ \\
\hline & Argamassa de reboco & 0,5 & 0 & $\begin{array}{l}\text { Desconsiderada na otimização. } \\
\text { Apenas nos custos. }\end{array}$ \\
\hline & $\begin{array}{l}\text { Pintura cor branco- } \\
\text { fosco (absortância } \\
36,7 \% \text { ) }\end{array}$ & & 0 & $\begin{array}{l}\text { A absortância da tinta foi usada } \\
\text { como absortância do revestimento } \\
\text { externo na otimização. }\end{array}$ \\
\hline \multirow{4}{*}{$\begin{array}{l}\text { Piso térreo e } \\
\text { revestimento } \\
\text { dos pisos do } \\
\mathbf{1}^{\circ} \text { pav. }\end{array}$} & Radier concreto & 10 & 10 & \\
\hline & $\begin{array}{l}\text { Argamassa de } \\
\text { emboço }\end{array}$ & 2,5 & 2,5 & \\
\hline & $\begin{array}{l}\text { Argamassa de } \\
\text { assentamento do piso }\end{array}$ & & 0 & $\begin{array}{l}\text { Desconsiderada na otimização. } \\
\text { Apenas nos custos. }\end{array}$ \\
\hline & Piso cerâmico & & 0,1 & \\
\hline Lajes & Laje concreto & variável & variável & \\
\hline \multirow{4}{*}{$\begin{array}{l}\text { Cobertura } \\
\text { Cerâmica }\end{array}$} & Terças & & 0 & \multirow{3}{*}{$\begin{array}{l}\text { Desconsiderados na otimização. } \\
\text { Apenas nos custos. }\end{array}$} \\
\hline & Caibros & & 0 & \\
\hline & Ripas & & 0 & \\
\hline & Telha de barro & & 1,0 & \\
\hline \multirow{6}{*}{$\begin{array}{l}\text { Cobertura } \\
\text { verde }\end{array}$} & Laje de concreto & variável & variável & \\
\hline & $\begin{array}{l}\text { Manta } \\
\text { impermeabilizante a } \\
\text { base de asfalto } \\
\text { modificado com } \\
\text { polímeros de APP }\end{array}$ & & 0 & $\begin{array}{l}\text { Desconsiderado na otimização. } \\
\text { Apenas nos custos. }\end{array}$ \\
\hline & Argamassa armada & 1,0 & 1,0 & $\begin{array}{l}\text { Considerado um emboço de } 1,0 \\
\mathrm{~cm} \text { na otimização. }\end{array}$ \\
\hline & Brita ou seixo & 5,0 & 5,0 & \\
\hline & Terra argilosa seca & 5,0 & 5,0 & \\
\hline & Vegetação & & 0 & $\begin{array}{l}\text { A absortância e rugosidade da } \\
\text { vegetação foram consideradas } \\
\text { como propriedades da camada } \\
\text { externa utilizada na otimização } \\
\text { (terra argilosa seca). }\end{array}$ \\
\hline Janelas & $\begin{array}{l}\text { Vidro transparente } \\
\text { comum }\end{array}$ & 0,3 & 0,3 & \\
\hline
\end{tabular}

Fonte: Ordenes et al. (2003), ABNT (2003) e Sorgato (2011). 


\section{Parâmetros da otimização}

Foram determinadas oito variáveis/parâmetros de otimização para este projeto, referentes à forma da edificação (dimensão dos ambientes de permanência prolongada) e à espessura da laje estrutural.

A geometria da edificação foi criada a partir da origem dos eixos $x, y$ e $z$, determinado como o marcador da gramática da forma segundo Trescak, Esteva e Rodriguez (2012), com suas variáveis determinadas como uma expansão dos ambientes a partir de x, y (Figura 4) e z (Figura 5). As dimensões mínimas dos ambientes foram calculadas de acordo com áreas mínimas estabelecidas pelo Código de Obras de Viçosa (PREFEITURA..., 2015) para ambientes residenciais e conforme restrições para sua funcionalidade de acordo com o projeto proposto, como adequação para inserção de uma escada e adequação às restrições de criação da forma do Archsim. Os parâmetros e intervalos de variação foram:

(a) Sala Escrit Eixo X: 4,1 - 7,0 m;

(b) D1 D2 D3 D4 Eixo X: 2,5 - 6,0 m;

(c) Sala D1 D3 Eixo Y: 4,9 - 6,0 m;

(d) Escrit D2 D4 Eixo Y: 2,5 - 6,0 m;

(e) Pé direito térreo: 2,7 - 3,7 m;

(f) Pé direito 1 pav: 2,7 - 3,7 m;

(g) Altura telhado: 1,0 - 3,0 m; e

(h) Espessura laje: 0,05 - 0,25 m.

Os parâmetros relativos às dimensões dos ambientes, pé-direito e altura da cumeeira do telhado foram criados para avaliar a influência da forma no desempenho térmico da edificação. O número de parâmetros foi limitado devido ao custo computacional do processo de otimização para alcance da convergência de soluções e para simplificação do cálculo de custos dos materiais. Como um primeiro passo de integração entre desempenho térmico e compatibilização com desempenho estrutural neste projeto, a espessura da laje foi considerada como um parâmetro na otimização, sendo o seu desempenho estrutural uma restrição para a otimização da espessura. O parâmetro espessura da laje era independente desde que atendesse à restrição estrutural criada, que determinava um valor mínimo admissível para as dimensões dos ambientes em questão e cargas.

A altura do telhado foi definida como a distância entre a laje do primeiro pavimento e a cumeeira (Figura 5), localizada sempre no encontro entre D3 e D4.

As aberturas para iluminação e ventilação foram definidas como porcentagens em relação às áreas dos pisos; portanto, não foram consideradas como parâmetros de entrada independentes na otimização.

\section{Restrições estruturais}

O dimensionamento das lajes foi realizado a partir da técnica de lajes retangulares armadas em cruz pelo processo Marcus, adaptado para atender à NBR 6118 (ABNT, 2014). Os fatores dimensionadores considerados foram as flechas obtidas na laje a partir das cargas aplicadas e a espessura dela. Assim, consideraram-se aceitáveis apenas espessuras de lajes que gerassem um valor menor ou igual à flecha máxima estabelecida por norma, atendendo aos requisitos de estado-limite de utilização.

Figura 5 - Corte do modelo real e corte esquemático

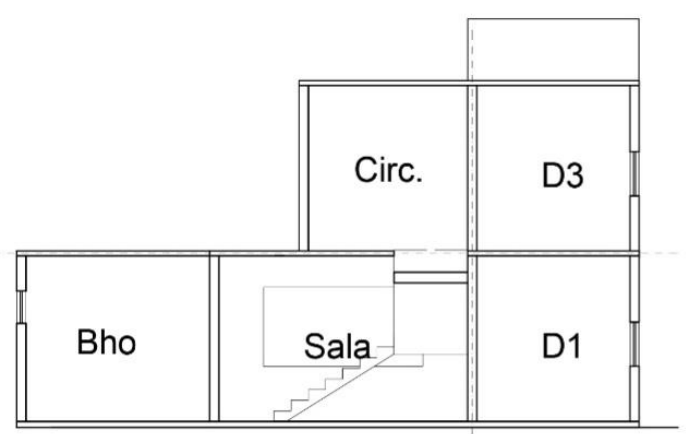

Corte A-A'

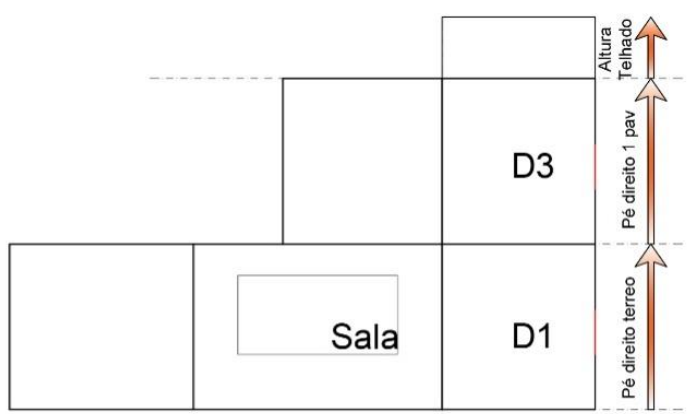

Corte Esquemático A-A'

274 Fonseca, L. P. G.; Nunes, V. D. L.; Santana, L. O.; Carlo, J. C.; César Júnior, K. M. L. 
As cargas consideradas foram:

(a) revestimentos: $1 \mathrm{kN} / \mathrm{m}^{2}$, conforme prática profissional;

(b) cargas permanentes verticais seguindo a NBR 6120 (ABNT, 1980), considerando então 1,5 $\mathrm{kN} / \mathrm{m}^{2}$ para salas e dormitórios e $2 \mathrm{kN} / \mathrm{m}^{2}$ para o escritório;

(c) peso próprio da laje: calculado durante o processo de dimensionamento através de loopings de programação;

(d) terraço verde: $4 \mathrm{kN} / \mathrm{m}^{2}$, considerando o peso da argamassa armada, brita 2 em sua massa unitária solta conforme a NBR NM 45 (ABNT, 2004) e solo como valor padrão de peso específico natural de $20 \mathrm{kN} / \mathrm{m}^{3}$, para solo úmido; e

(e) telhado: $70 \mathrm{kN} / \mathrm{m}^{2}$, apoiado na laje a partir de pontaletes, que são considerados cargas pontuais, e não cargas distribuídas; logo, a carga foi uma estimativa geral.

A resolução do dimensionamento foi realizada a partir de um componente criado no Visual Basic, para otimizar a equação e deixar o arquivo ".gh" (formatos dos arquivos salvos do Grasshopper) mais leve, a fim de reduzir o tempo de simulação.

Considerando a facilidade de se usar uma espessura única para lajes vizinhas pelo método construtivo de lajes maciças em estruturas de concreto armado - levando em conta a possibilidade de reutilização das formas e gerando, assim, grande economia no processo -, a espessura mínima adotada foi sempre o maior resultado obtido do dimensionamento. Ainda, mesmo que as espessuras mínimas de lajes sejam influenciadas pelas dimensões nos eixos $x$ e $y$ da geometria, a análise de desempenho térmico pode alterar a espessura mínima estrutural durante a otimização.

\section{Determinação dos custos: objetivo 1}

Foi determinado apenas o custo dos ambientes de permanência prolongada (APPs) da edificação, considerando-se os materiais componentes dos elementos de vedação e da estrutura das lajes e telhado que seriam otimizados. Os materiais são apresentados na Tabela 2.

Tabela 2 - Materiais utilizados nos componentes da envoltória e seus custos (Continua...)

\begin{tabular}{|c|c|c|c|}
\hline Elemento & Componentes & Detalhamento dos componentes & $\begin{array}{c}\text { Custo } \\
(\mathbf{R} \$ / \text { un. })\end{array}$ \\
\hline \multirow{6}{*}{$\begin{array}{l}\text { Piso radier } \\
\text { e pisos D3 e } \\
\text { D4 }\end{array}$} & \multirow{2}{*}{$\begin{array}{l}\text { Radier e piso de } \\
\text { concreto armado }\end{array}$} & $\begin{array}{l}\text { Concreto usinado bombeável, C25, com brita } 0 \\
\text { e } 1 \text {, slump }=130+/-20 \mathrm{~mm}\end{array}$ & $280,81 / \mathrm{m}^{3}$ \\
\hline & & Armadura de aço CA-50, 10,0 mm, vergalhão & $3,68 / \mathrm{kg}$ \\
\hline & \multirow{2}{*}{$\begin{array}{l}\text { Emboço de } \\
\text { regularização do piso } \\
\text { Traço 1:4 }\end{array}$} & Cimento CP-II 32 & $0,43 / \mathrm{kg}$ \\
\hline & & $\begin{array}{l}\text { Areia grossa - Posto Jazida/fornecedor (sem } \\
\text { frete) }\end{array}$ & $70,00 / \mathrm{m}^{3}$ \\
\hline & \multirow[b]{2}{*}{ Piso cerâmico } & Argamassa de assentamento do piso & $0,48 / \mathrm{kg}$ \\
\hline & & $\begin{array}{l}\text { Piso em cerâmica esmaltada Extra, PEI maior } \\
\text { ou igual a } 4 \text {, formato maior que } 2025 \mathrm{~cm}^{2}\end{array}$ & $37,61 / \mathrm{m}^{2}$ \\
\hline \multirow{2}{*}{$\begin{array}{l}\text { Lajes D3 e } \\
\text { D4 }\end{array}$} & \multirow{2}{*}{$\begin{array}{l}\text { Laje de concreto } \\
\text { armado }\end{array}$} & $\begin{array}{l}\text { Concreto usinado bombeável, C25, com brita } 0 \\
\text { e } 1 \text {, slump }=130+/-20 \mathrm{~mm}\end{array}$ & $280,81 / \mathrm{m}^{3}$ \\
\hline & & Armadura de aço CA-50, 10,0 mm, vergalhão & $3,68 / \mathrm{kg}$ \\
\hline \multirow{8}{*}{$\begin{array}{l}\text { Cobertura } \\
\text { verde }\end{array}$} & \multirow{2}{*}{$\begin{array}{l}\text { Laje de concreto } \\
\text { armado }\end{array}$} & $\begin{array}{l}\text { Concreto usinado bombeável, C25, com brita } 0 \\
\text { e } 1 \text {, slump }=130+/-20 \mathrm{~mm}\end{array}$ & $280,81 / \mathrm{m}^{3}$ \\
\hline & & Armadura de aço CA-50, 10,0 mm, vergalhão & $3,68 / \mathrm{kg}$ \\
\hline & $\begin{array}{l}\text { Manta } \\
\text { impermeabilizante }\end{array}$ & $\begin{array}{l}\text { Manta impermeabilizante à base de asfalto } \\
\text { modificado c/ polímeros de APP tipo Torodim } 4 \\
\text { mm Viapol ou equiv. }\end{array}$ & $27,68 / \mathrm{m}^{2}$ \\
\hline & \multirow{2}{*}{$\begin{array}{l}\text { Argamassa armada } \\
\text { Traço } 1: 4\end{array}$} & Cimento CP-II 32 & $0,43 / \mathrm{kg}$ \\
\hline & & $\begin{array}{l}\text { Areia grossa - Posto Jazida/fornecedor (sem } \\
\text { frete) }\end{array}$ & $70,00 / \mathrm{m}^{3}$ \\
\hline & Brita & $\begin{array}{l}\text { Pedra britada N. } 2 \text { (19 a } 38 \mathrm{~mm} \text { ) Posto } \\
\text { Pedreira/fornecedor, sem frete }\end{array}$ & $57,50 / \mathrm{m}^{3}$ \\
\hline & Terra & Terra vegetal & $70,50 / \mathrm{m}^{3}$ \\
\hline & Grama & Grama Esmeralda em placas, sem plantio & $6,30 / \mathrm{m}^{2}$ \\
\hline
\end{tabular}


Tabela 2 - Materiais utilizados nos componentes da envoltória e seus custos (continuação)

\begin{tabular}{|c|c|c|c|}
\hline Elemento & Componentes & Detalhamento dos componentes & $\begin{array}{c}\text { Custo } \\
(\mathbf{R} \$ / \mathbf{u n} .)\end{array}$ \\
\hline \multirow{4}{*}{$\begin{array}{l}\text { Telhado } \\
\text { cerâmico }\end{array}$} & $\begin{array}{l}\text { Estrutura básica } \\
\text { (empenas, pontaletes e } \\
\text { terças) }\end{array}$ & $\begin{array}{l}\text { Peças de madeira de lei } 7,5 \text { x } 15 \mathrm{~cm} \text { ( } 3 " \text { X 6" ), } \\
\text { não aparelhada }\end{array}$ & $26,57 / \mathrm{m}$ \\
\hline & Caibros & $\begin{array}{l}\text { Peças de madeira de lei } 5 \text { × } 6 \text { cm, não } \\
\text { aparelhada }\end{array}$ & $6,34 / \mathrm{m}$ \\
\hline & Ripas & $\begin{array}{l}\text { Peças de madeira de lei } 2,5 \text { x } 5 \mathrm{~cm} \text {, não } \\
\text { aparelhada }\end{array}$ & $3,31 / \mathrm{m}$ \\
\hline & Telhas & $\begin{array}{l}\text { Telha cerâmica do tipo colonial, comprimento } \\
\text { de } 44 \mathrm{~cm} \text {, rendimento de } 26 \text { telhas } / \mathrm{m}^{2}\end{array}$ & $0,82 /$ un \\
\hline \multirow{17}{*}{ Paredes } & Pintura & $\begin{array}{l}\text { Pintura em tinta acrílica Premium, cor branco- } \\
\text { fosco }\end{array}$ & $14,81 / 1$ \\
\hline & \multirow{3}{*}{$\begin{array}{l}\text { Argamassa de reboco } \\
\text { Traço 1:2:9 }\end{array}$} & Cimento CP-II 32 & $0,43 / \mathrm{kg}$ \\
\hline & & Cal hidratada CH-I para argamassas & $0,50 / \mathrm{kg}$ \\
\hline & & $\begin{array}{l}\text { Areia média - Posto Jazida/fornecedor (sem } \\
\text { frete) }\end{array}$ & $58,33 / \mathrm{m}^{3}$ \\
\hline & \multirow{3}{*}{$\begin{array}{l}\text { Argamassa de emboço } \\
\text { Traço 1:2:9 }\end{array}$} & Cimento CP-II 32 & $0,43 / \mathrm{kg}$ \\
\hline & & Cal hidratada CH-I para argamassas & $0,50 / \mathrm{kg}$ \\
\hline & & $\begin{array}{l}\text { Areia média - Posto Jazida/fornecedor (sem } \\
\text { frete) }\end{array}$ & $58,33 / \mathrm{m}^{3}$ \\
\hline & \multirow[b]{2}{*}{ Chapisco Traço 1:3 } & Cimento CP-II 32 & $0,43 / \mathrm{kg}$ \\
\hline & & $\begin{array}{l}\text { Areia grossa - Posto Jazida/fornecedor (sem } \\
\text { frete) }\end{array}$ & $70,00 / \mathrm{m}^{3}$ \\
\hline & Blocos cerâmicos & $\begin{array}{l}\text { Bloco cerâmico de vedação, } 8 \text { furos, de } \\
9 \times 19 \times 19 \mathrm{~cm}\end{array}$ & $0,44 /$ un \\
\hline & \multirow{3}{*}{$\begin{array}{l}\text { Argamassa de } \\
\text { assentamento dos } \\
\text { blocos cerâmicos } \\
\text { Traço } 1: 2: 8\end{array}$} & Cimento CP-II 32 & $0,43 / \mathrm{kg}$ \\
\hline & & Cal hidratada CH-I para argamassas & $0,50 / \mathrm{kg}$ \\
\hline & & $\begin{array}{l}\text { Areia grossa - Posto Jazida/fornecedor (sem } \\
\text { frete) }\end{array}$ & $70,00 / \mathrm{m}^{3}$ \\
\hline & Chapisco Traço 1: 3 & \multirow{3}{*}{\multicolumn{2}{|c|}{ Já descrito anteriormente }} \\
\hline & $\begin{array}{l}\text { Argamassa de emboço } \\
\text { Traço 1:2:9 }\end{array}$ & & \\
\hline & $\begin{array}{l}\text { Argamassa de reboco } \\
\text { Traço 1:2:9 }\end{array}$ & & \\
\hline & Pintura & $\begin{array}{l}\text { Pintura em tinta acrílica Premium, cor Branco } \\
\text { Fosco }\end{array}$ & $14,81 / 1$ \\
\hline Janelas & $\begin{array}{l}\text { Janelas de alumínio } \\
\text { com vidro simples }\end{array}$ & $\begin{array}{l}\text { Janela de correr em alumínio, série } 25 \text {, sem } \\
\text { bandeira, com } 4 \text { folhas para vidro, (duas fixas e } \\
\text { duas móveis) } 1,60 \text { x 1,10 m (incluso guarnição } \\
\text { e vidro liso) }\end{array}$ & $334,77 / \mathrm{m}^{2}$ \\
\hline
\end{tabular}

Fonte: Sinapi Minas Gerais do mês de agosto (CAIXA...; INSTITUTO..., 2015).

O consumo de materiais foi relacionado com as áreas das superfícies dos elementos de vedação ou seus volumes, de modo que, sempre que a volumetria se modificasse durante a otimização, os custos de cada componente da envoltória se adequariam às alterações (Figura 6).

Para o cálculo da estrutura do telhado (pontaletes, empenas e terças) foram criadas condições que satisfizessem recomendações estruturais dentro do intervalo dos parâmetros estabelecidos para as dimensões em planta dos ambientes adjacentes. Foram criadas regras determinando o número de pontaletes e terças de acordo com o vão do telhado, que havia sido parametrizado. Definido-se que, para até $3,5 \mathrm{~m}$, deveriam existir pontaletes apenas nas duas extremidades do vão no sentido da cumeeira. Acima disso, deveria haver também pontaletes centrais, considerando um vão máximo de $6,0 \mathrm{~m}$. O número de terças e de pontaletes no sentido das águas do telhado foi definido de acordo com a seguinte regra: até $2,5 \mathrm{~m}$, apenas cumeeira, frechal e pontalete central; entre $2,5 \mathrm{~m}$ e $5,0 \mathrm{~m}$, cumeeira, frechal e uma terça e pontalete intermediários; entre 5,0 m e 6,0 m, cumeeira, 
frechal e duas terças e pontaletes. O comprimento linear das madeiras da estrutura foi obtido e multiplicado pelo custo das peças, o que gerou um custo por metro linear de madeira. Para os caibros e ripas foram utilizados consumos por área, considerando-se um espaçamento entre caibros de $50 \mathrm{~cm}$, e para as ripas, o comprimento das telhas. O primeiro objetivo da otimização seria encontrar a edificação com o menor custo considerando-se o custo total dos materiais citados.

\section{Indicadores de desempenho térmico: objetivo 2}

Na primeira otimização, o indicador para avaliação do desempenho térmico dos ambientes da edificação foi uma relação entre os graus-hora de resfriamento, recomendado pelo RTQ-R (INSTITUTO..., 2012) para avaliação do desempenho durante o verão, e os graus hora de aquecimento.

Embora o RTQ-R (INSTITUTO..., 2012) exija o consumo para aquecimento como indicador para avaliação do desempenho da envoltória no inverno, o Archsim não modela o ar-condicionado requerido pelo regulamento em seu método de simulação, o que invalida a aplicação do método de etiquetagem na otimização. Portanto, os graushora de aquecimento foram utilizados em substituição.
As temperaturas-base para GHR e GHA foram respectivamente $26^{\circ} \mathrm{C}$, conforme o RTQ-R (INSTITUTO..., 2012), e $18{ }^{\circ} \mathrm{C}$, conforme a Standard $55^{10}$ (AMERICAN..., 2010) e Givoni (1992). A média ponderada dos graus-hora pela área dos ambientes foi calculada conforme as Equações 1 e 2. Em seguida, os dois indicadores de desempenho térmico foram combinados conforme a Equação 3, estabelecendo-se o segundo objetivo da primeira otimização: minimizar os graus-hora da envoltória da edificação ${ }^{11}$.

$$
\begin{aligned}
\mathrm{GH}_{\text {Resf }} & =\frac{\left(\sum\left(A m b_{\mathrm{GHResf}} \times \mathrm{Amb}_{\text {área }}\right)\right)}{\sum \text { Ambárea }_{\text {árá }}} \\
\mathrm{GH}_{\mathrm{Aq}} & =\frac{\left(\sum\left(A m b_{\mathrm{GHAq}} \times \mathrm{Amb}_{\text {área }}\right)\right)}{\sum \mathrm{Amb}_{\text {área }}}
\end{aligned}
$$

Sendo:

$\mathrm{GH}_{\text {Resf }}$ - Graus-hora de resfriamento da envoltória; $\mathrm{GH}_{\mathrm{Aq}}$ - Graus-hora de aquecimento da envoltória;

$\mathrm{Amb}_{\mathrm{GHResf}}$ - Graus-hora de resfriamento de cada ambiente, sendo os ambientes: Sala, Escritório, D1, D2, D3 e D4;

$\mathrm{Amb}_{\mathrm{GHAq}}$ - Graus-hora de aquecimento de cada ambiente, sendo os ambientes: Sala, Escritório, D1, D2, D3 e D4; e

$\mathrm{Amb}_{\text {área }}$ - Área dos ambientes.

Figura 6 - Exemplo de modelagem do cálculo do custo das lajes

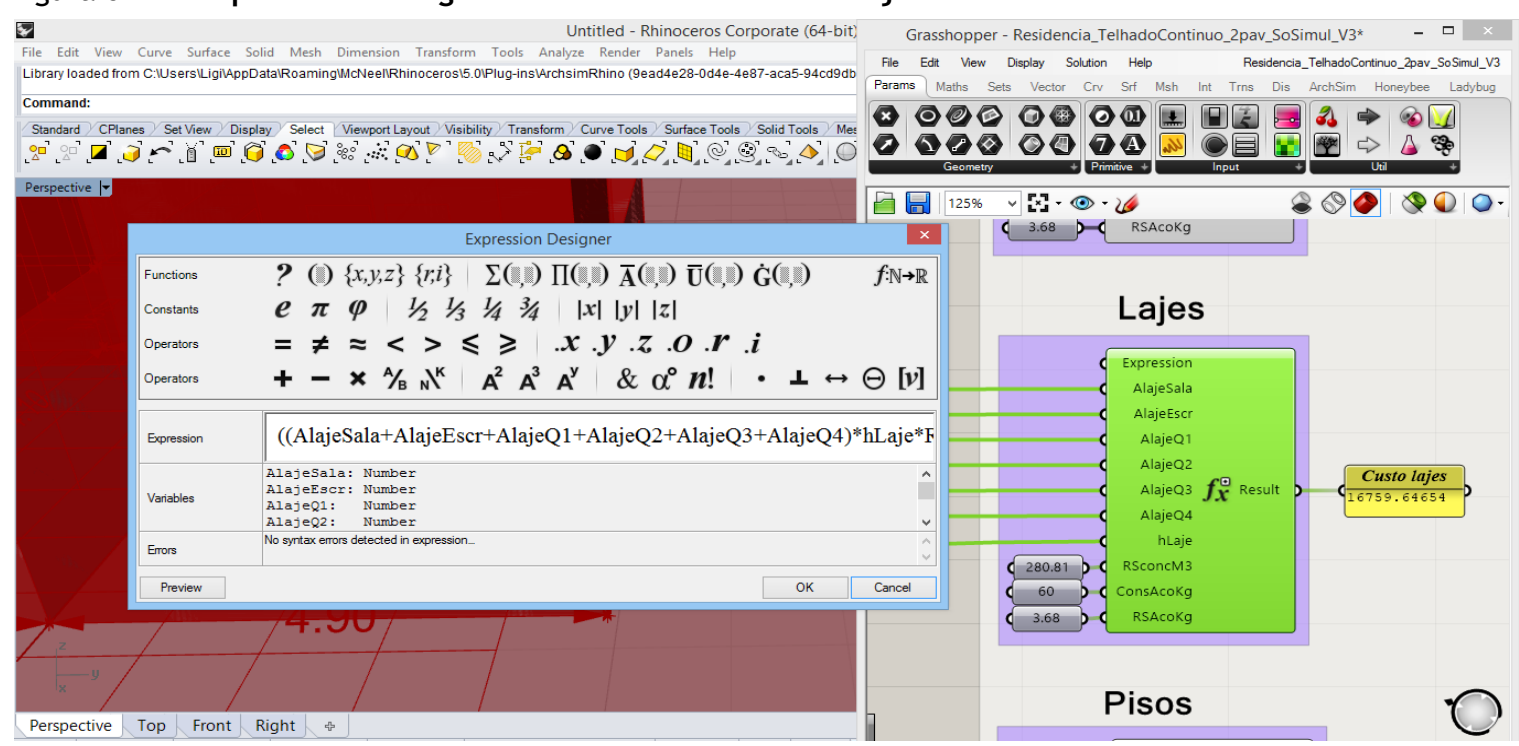

${ }^{10} \mathrm{~A}$ Standard 55 (AMERICAN..., 2010) indica $18,5^{\circ} \mathrm{C}$ como temperatura mínima de conforto para ambiente interno naturalmente ventilado para $90 \%$ de aceitabilidade e $17^{\circ} \mathrm{C}$ para $80 \%$.

${ }^{11}$ Excluídos os ambientes de permanência transitória: cozinha e banheiro. 
A equação de determinação do desempenho térmico da edificação baseou-se nos pesos estabelecidos pelo RTQ-R (INSTITUTO..., 2012) para determinação do equivalente numérico da envoltória da edificação para a Zona Bioclimática 3 (Equação 3):

$\mathrm{GH}_{\mathrm{Env}}=0,64 \times \mathrm{GH}_{\text {Resf }}+0,36 \times \mathrm{GH}_{\mathrm{Aq}}$

Eq. 3

Sendo:

$\mathrm{GH}_{\mathrm{Env}}$ - Graus-hora da envoltória.

Após a análise dos resultados obtidos na primeira otimização, que indicaram que para o clima de Viçosa, MG, a influência do indicador de desempenho para verão era muito pequena em comparação com o indicador de desempenho para inverno, foi conduzida uma nova otimização, em que apenas os graus-hora de aquecimento foram contabilizados. Foi utilizada a Equação 2 para avaliação do desempenho térmico da edificação para a segunda etapa. De fato, Guimarães e Carlo (2011) identificaram que o clima de Viçosa proporciona maior percentual de desconforto por frio, $48,2 \%$, do que por calor, $13,4 \%$ (Figura 7).

\section{Método de simulação}

Após modelada a edificação e construídas as equações que determinam o seu custo, os ambientes foram conectados ao Archsim transformando-se em zonas térmicas. O Archsim envia as informações geradas no Grasshopper para o Energy Plus e recebe seus dados de saída transferindo-os ao Grasshopper.

Segundo o RTQ-R (INSTITUTO... 2012), para a simulação, deve ser considerada uma ocupação mínima de 2 pessoas por dormitório, e para a sala deve ser considerado que esta seja ocupada por todos os residentes. O escritório teve seu padrão de ocupação definido como de uma sala. No entanto, devido a restrições do Archsim, a taxa de ocupação só pode ser definida em função da área dos ambientes. Assim, foi determinada uma taxa de ocupação variando de 4 a 0,70 pessoa por dormitório; e para a sala e o escritório a ocupação variou de 8 a 1,40 pessoa. Este foi o aspecto mais discrepante no uso do Archsim para o setor residencial. Embora a ocupação tenha se tornado irreal quando a residência tem grandes dimensões, esta limitação foi considerada aceitável para que a residência de pequenas dimensões não estivesse desprovida de ocupação.

Os padrões de uso de ocupação, da iluminação e dos equipamentos foram criados de acordo com o estabelecido pelo RTQ-R (INSTITUTO..., 2012) para seu método de simulação, assim como os parâmetros de ventilação natural.

A simulação foi executada para o ano completo, com o arquivo climático de Viçosa, MG (GUIMARÃES; CARLO, 2011). A área efetiva de ventilação foi de $45 \%$ para janelas e $90 \%$ para portas, com temperatura de setpoint $20{ }^{\circ} \mathrm{C}$ para controle de abertura das janelas e com portas permanentemente abertas. $\mathrm{O}$ coeficiente de descarga para todas as aberturas foi de 0,6 (INSTITUTO..., 2012).

Os dados de saída extraídos a cada simulação do Energy Plus foram as temperaturas operativas horárias de cada ambiente. Para a primeira otimização, o Grasshopper calculou os graus-hora, ponderou-os e gerou os graus-hora da envoltória, número a ser otimizado. Na segunda otimização, foram extraídos apenas os graus-hora de aquecimento para serem otimizados.

\section{Escolha dos casos otimizados}

Após finalizada a criação do modelo e das equações que geraram os objetivos das otimizações, estes últimos, mais os parâmetros das dimensões dos ambientes, foram conectados ao plug-in Octopus (versão 0.3.5), o motor da otimização. Todos os casos produzidos no Grasshopper pelo Octopus foram simulados no Energy Plus através do Archsim.

Figura 7 - Temperaturas de bulbo seco mínimas, médias e máximas diárias, relacionadas aos limites de conforto de Givoni para Viçosa - MG

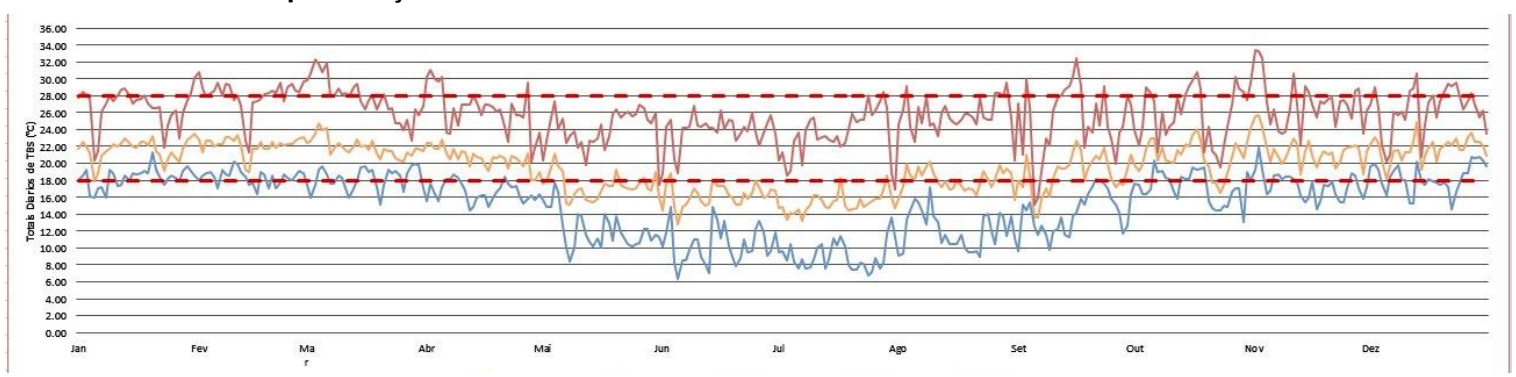

Fonte: Guimarães e Carlo (2011). 
A convergência de soluções foi utilizada como critério de parada. O ponto de convergência foi definido através da observação do gráfico fornecido pelo Octopus. Além dos dois objetivos do projeto, foi definido um terceiro: diversificação dos parâmetros, a fim de garantir que o motor de otimização fizesse uma busca por todo o espaço de soluções e não corresse o risco de se prender a uma busca local, o que poderia levar a uma perda de soluções potenciais.

Após finalizados os processos de otimização, foram selecionados dois casos entre as gerações que compunham as soluções de Pareto do plug-in Octopus para cada otimização. $\mathrm{O}$ primeiro corresponde à volumetria com menor custo dos componentes construtivos, e o segundo, à edificação com o melhor desempenho térmico.

\section{Resultados e discussão}

O primeiro processo de OBS durou $95 \mathrm{~h}$, até encontrada a convergência pelo Octopus. Ao total foram criadas 99 gerações, cada uma composta de 200 soluções, com um total de 19.800 simulações (Figura 8).

Todas as soluções que compunham o Pareto Front determinadas pelo Octopus foram identificadas de acordo com suas gerações, sendo as de cor clara as primeiras gerações, e as mais escuras, as últimas (Figura 9), com 4.268 soluções. A maior densidade de soluções se encontra na fronteira que determina o Pareto Front, indicando a convergência de soluções, destacadas em vermelho (Figura 9). Entretanto, o Octopous se prendeu a soluções locais em alguns pontos além da curva de Pareto, representadas por manchas escuras além da curva de Pareto (Figura 9). Essas soluções, em amarelo na Figura 10, não foram consideradas como pertencentes ao Pareto Front na análise final.

Figura 8 - Edificação em suas menores e maiores dimensões
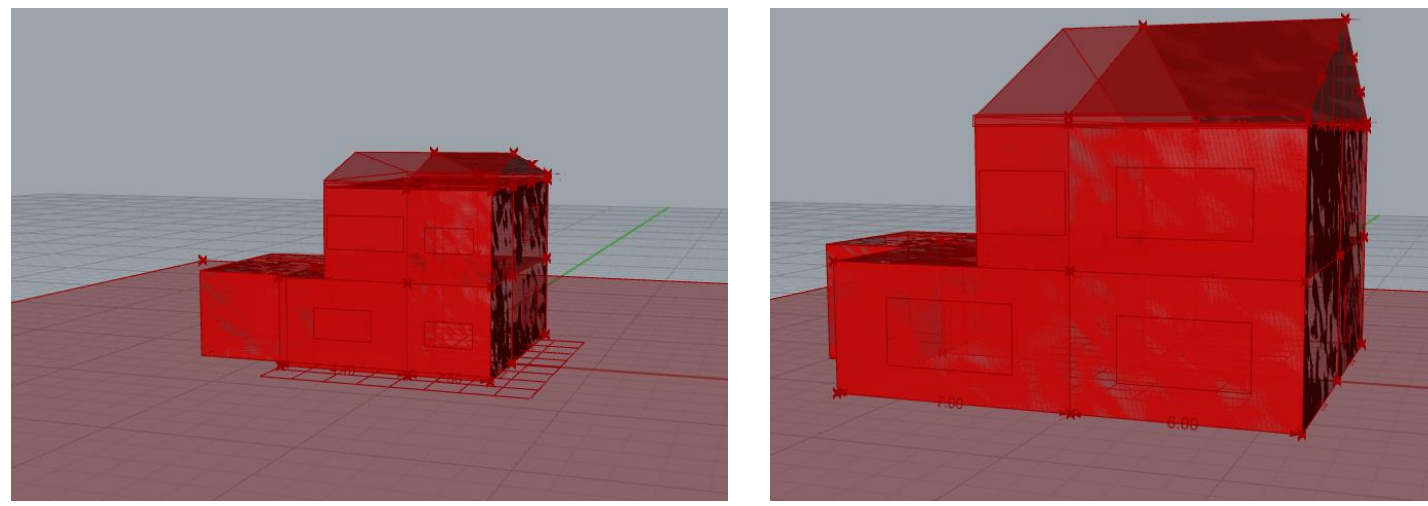

Figura 9 - Todas as soluções de Pareto das gerações criadas pelo Octopus durante o processo de otimização. Dentro da bolha vermelha, as soluções de Pareto consideradas para análise

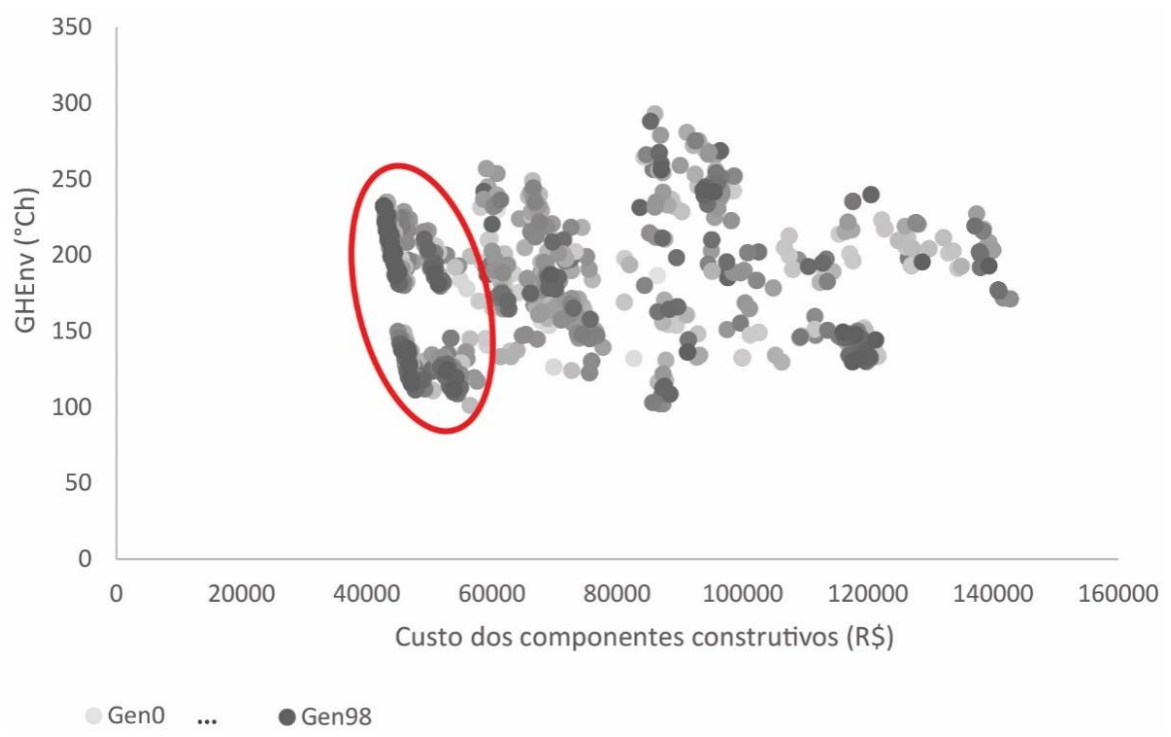


Os $\mathrm{GH}_{\text {Env }}$ variaram de $102,22{ }^{\circ} \mathrm{Ch}$ a $289,01{ }^{\circ} \mathrm{Ch}$, e os custos, de $\mathrm{R} \$ 42.718,06$ a $\mathrm{R} \$ 145.480,50$, o que corresponde a intervalos de 186,8 unidades de graus Celsius.hora e 102.762,44 unidades de reais respectivamente. Simplificando, os intervalos serão chamados de $187^{\circ} \mathrm{Ch}$ e de R $\$ 103$ mil.

A partir das soluções de Pareto identificadas na Figura 10 foram escolhidas as soluções $\mathrm{C} 1$ (de menor custo dos componentes construtivos) e $\mathrm{C} 2$ (de menor $\mathrm{GH}_{\mathrm{Env}}$ ).

O Caso 1 apresentou o menor custo dos componentes construtivos, de $\mathrm{R} \$ 42.718,06$, e os $\mathrm{GH}_{\mathrm{Env}}$ de $233,33{ }^{\circ} \mathrm{Ch}$. Este caso apareceu na última geração de soluções (Gen 98). Os parâmetros que levaram a esses resultados são apresentados na Tabela 3 e na Figura 11. A espessura da laje no parâmetro de entrada definido pelo Octopus foi de
$5 \mathrm{~cm}$, porém, com as restrições estruturais empregadas sobre ela, a espessura final admitida foi de $10 \mathrm{~cm}$.

Percebe-se pela Figura 10, que o desempenho do Caso 1 é o pior dos casos apresentados nas soluções de Pareto. No entanto, comparado aos demais casos criados (Figura 9), 233,33 ${ }^{\circ} \mathrm{Ch}$ é cerca de $70 \%$ dos $187^{\circ} \mathrm{Ch}$.

O Caso 2 apresentou melhor desempenho térmico entre as soluções de Pareto (Figura 10). Esta solução apresentou $\mathrm{GH}_{\text {Env }}$ de113,05 ${ }^{\circ} \mathrm{Ch}$ e um custo total dos materiais construtivos de $\mathrm{R} \$$ 53.884,50, apenas $10,87 \%$ do intervalo de $\mathrm{R} \$ 103$ mil. Os parâmetros que levaram a estes resultados de custos são apresentados na Tabela 4 e na Figura 12 .

Figura 10 - 10\% das gerações de soluções iniciais (cinza) e $10 \%$ das gerações de soluções finais (vermelho e amarelo), mostram a convergência - as soluções em amarelo estiveram presentes nas gerações finais, porém foram descartadas pelos autores das soluções de Pareto (vermelho)

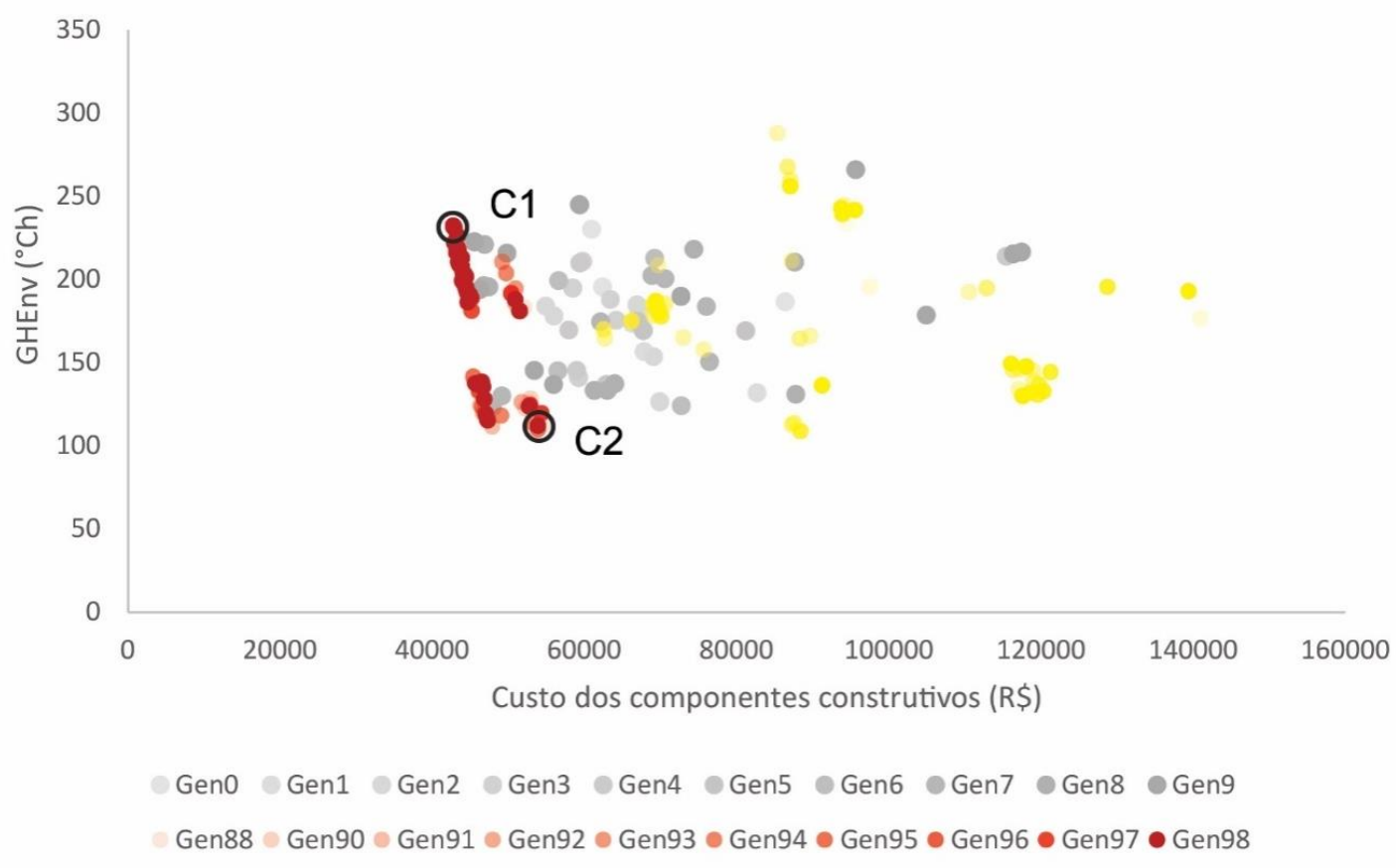

Tabela 3 - Parâmetros do Caso 1

\begin{tabular}{l|c}
\hline D1 D2 D3 D4 Eixo X & $2,5 \mathrm{~m}$ \\
Sala D1 D3 Eixo Y & $4,9 \mathrm{~m}$ \\
Escrit D2 D4 Eixo Y & $2,5 \mathrm{~m}$ \\
Sala Escrit Eixo X & $4,1 \mathrm{~m}$ \\
Pé-direito térreo & $2,7 \mathrm{~m}$ \\
Pé-direito 1 pav & $2,7 \mathrm{~m}$ \\
Altura telhado & $1,0 \mathrm{~m}$ \\
Espessura laje & $0,10 \mathrm{~m}$ \\
\hline
\end{tabular}

280 Fonseca, L. P. G.; Nunes, V. D. L.; Santana, L. O.; Carlo, J. C.; César Júnior, K. M. L. 
Figura 11 - Plantas do Caso 1

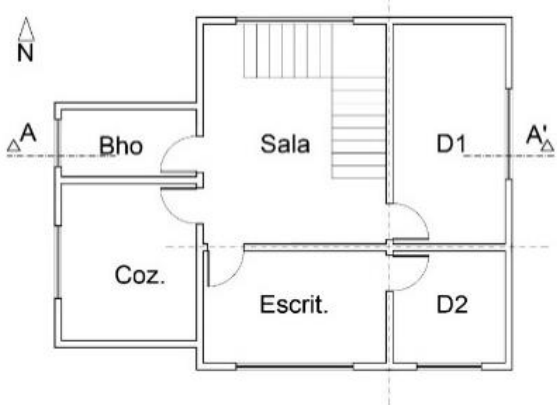

Planta Baixa Térreo

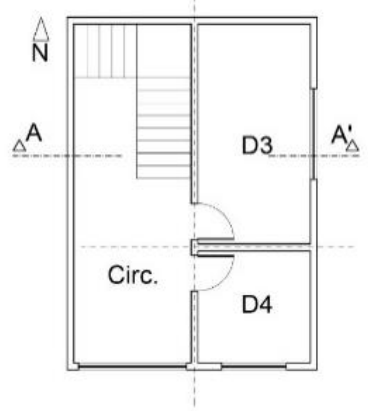

Planta Baixa 1 Pav.

Figura 12 - Plantas do Caso 2
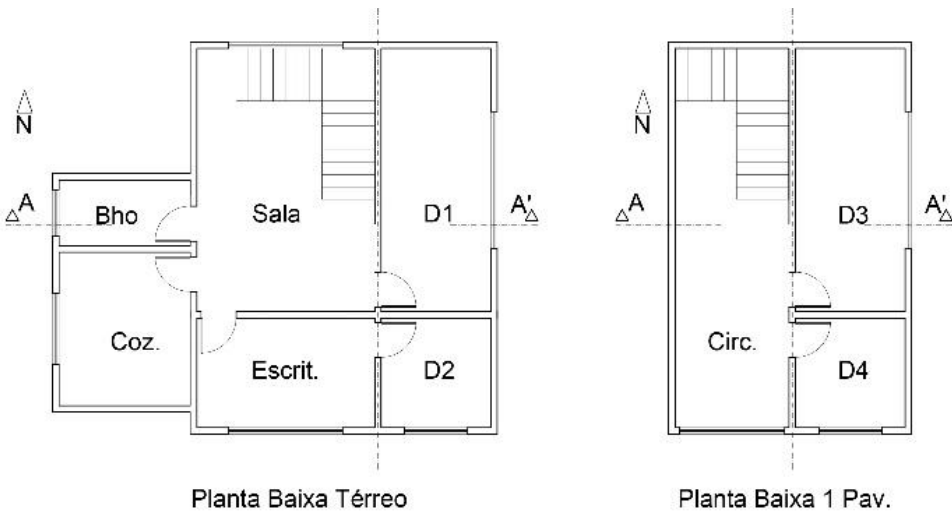

Tabela 4 - Parâmetros do Caso 2

\begin{tabular}{l|c}
\hline D1 D2 D3 D4 Eixo X & $2,5 \mathrm{~m}$ \\
Sala D1 D3 Eixo Y & $6,0 \mathrm{~m}$ \\
Escrit D2 D4 Eixo Y & $2,5 \mathrm{~m}$ \\
Sala Escrit Eixo X & $4,1 \mathrm{~m}$ \\
Pé direito térreo & $3,7 \mathrm{~m}$ \\
Pé direito 1 pav & $3,6 \mathrm{~m}$ \\
Altura telhado & $1,0 \mathrm{~m}$ \\
Espessura laje & $0,25 \mathrm{~m}$ \\
\hline
\end{tabular}

A solução que apresentou melhor desempenho térmico tem como características o pé-direito máximo para o térreo e quase máximo para o primeiro pavimento, e a altura do telhado mínima, o que leva à menor zona térmica sobre os dormitórios D3 e D4, localizados no primeiro pavimento. Essa solução também apresenta a maior espessura de laje, indicando a contribuição da inércia para a melhoria do desempenho da envoltória nas condições de projeto (laje com cobertura vegetal, laje coberta por telhado cerâmico e laje entre pavimentos). O escritório, com abertura voltada a sul, apresentou melhor desempenho ao ter menor área, assim como os dormitórios 2 e 4, com aberturas também voltadas a sul. A sala e os dormitórios 1 e 3, com aberturas voltadas a norte, leste e leste respectivamente, apresentaram melhor desempenho com maiores áreas.

$\mathrm{O}$ caso de menor $\mathrm{GH}_{\mathrm{Env}}$, que não fez parte da última geração de soluções do Octopus, ocorreu na geração 33, e suas características são apresentadas na Tabela 5. Ele apresentou $102,22{ }^{\circ} \mathrm{Ch}$, próximo do Caso 2, e um custo de R\$ 56.490,52, também próximo ao $\mathrm{C} 2$.

Percebe-se que tanto o Caso 2 como o caso de menor $\mathrm{GH}_{\mathrm{Env}}$, apresentaram como características em comum maior pé-direito e maior espessura de laje, indicando que estes parâmetros foram os maiores contribuintes para uma edificação que apresentasse bom desempenho térmico com baixo custo (cerca de $11 \%$ do intervalo de custos possível durante a otimização). 
Na Figura 13 é apresentada uma relação entre os GHR e GHA dos Casos 1 e 2 para cada APP. Percebe-se que ocorreu melhoria no desempenho térmico de todos os ambientes, tanto para inverno quanto para verão, com o aumento da espessura da laje e com o aumento do pé-direito. A partir dessa figura pôde-se perceber também que, para o clima de Viçosa, os graus-hora de resfriamento foram pouco significativos comparados com os graushora de aquecimento. Segundo o RTQ-R, como não há tabelas de classificação do nível de eficiência da envoltória pelo método de simulação para Viçosa, usa-se a tabela do método prescritivo, na qual, para a Zona Bioclimática 3 , qualquer resultado abaixo de $822^{\circ} \mathrm{Ch}$ para resfriamento já é considerado nível A. Portanto, esse resultado conduziu a uma segunda otimização, em que os objetivos foram obter a volumetria da edificação que apresentasse o melhor desempenho para inverno (menores graus-hora de aquecimento) e o menor custo dos componentes construtivos.

A segunda otimização durou 138 h, até que encontrada a convergência pelo Octopus. Ao todo foram criadas 137 gerações, com um total de 27.400 simulações (Figura 13).
Foram obtidas 9.335 soluções de Pareto. Assim como na primeira otimização, a maior densidade de soluções se encontra na fronteira que determina o Pareto Front (destacado na Figura 14), e estas correspondem às últimas gerações criadas pelo Octopus, indicando a convergência de soluções. $\mathrm{O}$ mesmo comportamento que o Octopus apresentou para a otimização 1 , com a busca por soluções locais além das soluções de Pareto, é mostrado na Figura 14. Essas soluções também foram descartadas das soluções que compõem o Pareto Front na análise final (Figura 15).

Os GHA variaram de $254,05^{\circ} \mathrm{Ch}$ a $803,97^{\circ} \mathrm{Ch}$, e os custos, de $\mathrm{R} \$ 42.718,06$ a $\mathrm{R} \$ 145.385,60$, o que corresponde a intervalos de 549,92 unidades de graus Celsius.hora e de 102.667,54 unidades de reais respectivamente. Simplificando, os intervalos serão chamados de $550{ }^{\circ} \mathrm{Ch}$ e de R\$ 103 mil.

A partir das soluções de Pareto identificadas na Figura 10 foram escolhidas as soluções C3 (de menor custo dos componentes construtivos) e $\mathrm{C} 4$ (de menor GHA).

Tabela 5 - Parâmetros para o caso de menor $\mathrm{GH}_{\mathrm{Env}}$

\begin{tabular}{l|l}
\hline D1 D2 D3 D4 Eixo X & $2,7 \mathrm{~m}$ \\
Sala D1 D3 Eixo Y & $6,0 \mathrm{~m}$ \\
Escrit D2 D4 Eixo Y & $2,5 \mathrm{~m}$ \\
Sala Escrit Eixo X & $4,1 \mathrm{~m}$ \\
Pé direito térreo & $3,7 \mathrm{~m}$ \\
Pé direito 1 pav & $3,7 \mathrm{~m}$ \\
Altura telhado & $2,9 \mathrm{~m}$ \\
Espessura laje & $0,25 \mathrm{~m}$ \\
\hline
\end{tabular}

Figura 13 - Desempenho térmico para verão e inverno para cada ambiente nos casos 1 e 2

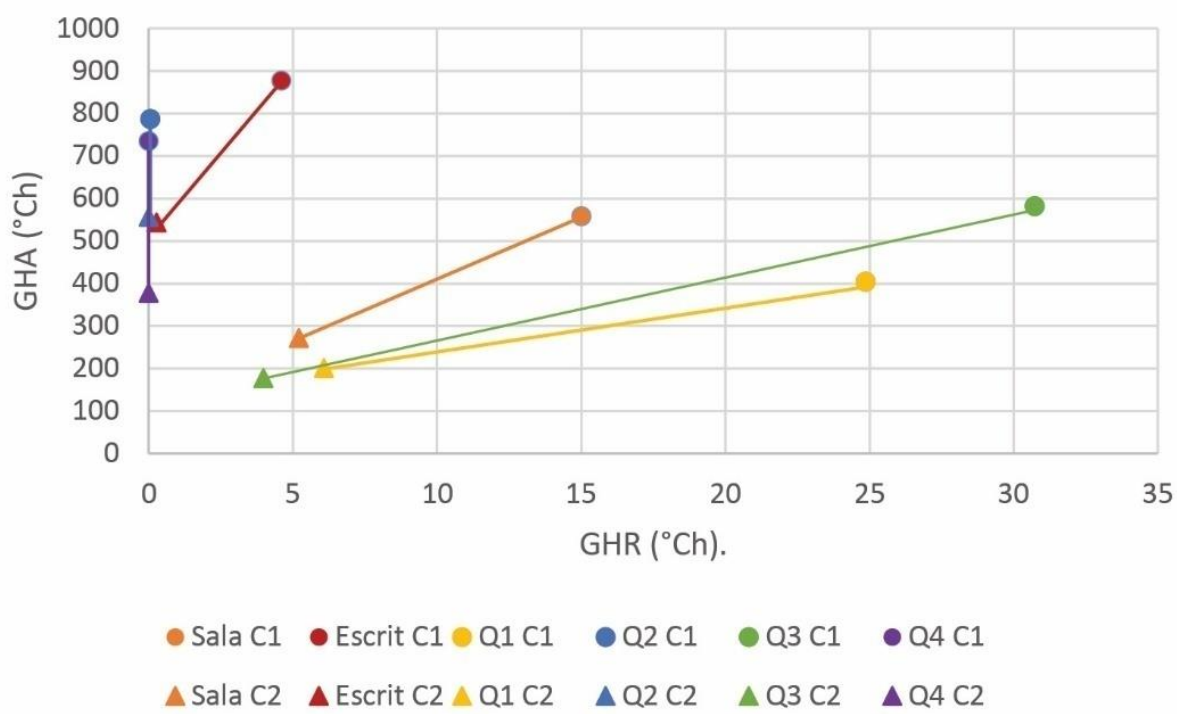

282 Fonseca, L. P. G.; Nunes, V. D. L.; Santana, L. O.; Carlo, J. C.; César Júnior, K. M. L. 
Figura 14 - Todas as soluções de Pareto das gerações criadas pelo Octopus durante o processo de otimização - dentro da bolha vermelha, as soluções de Pareto consideradas para análise

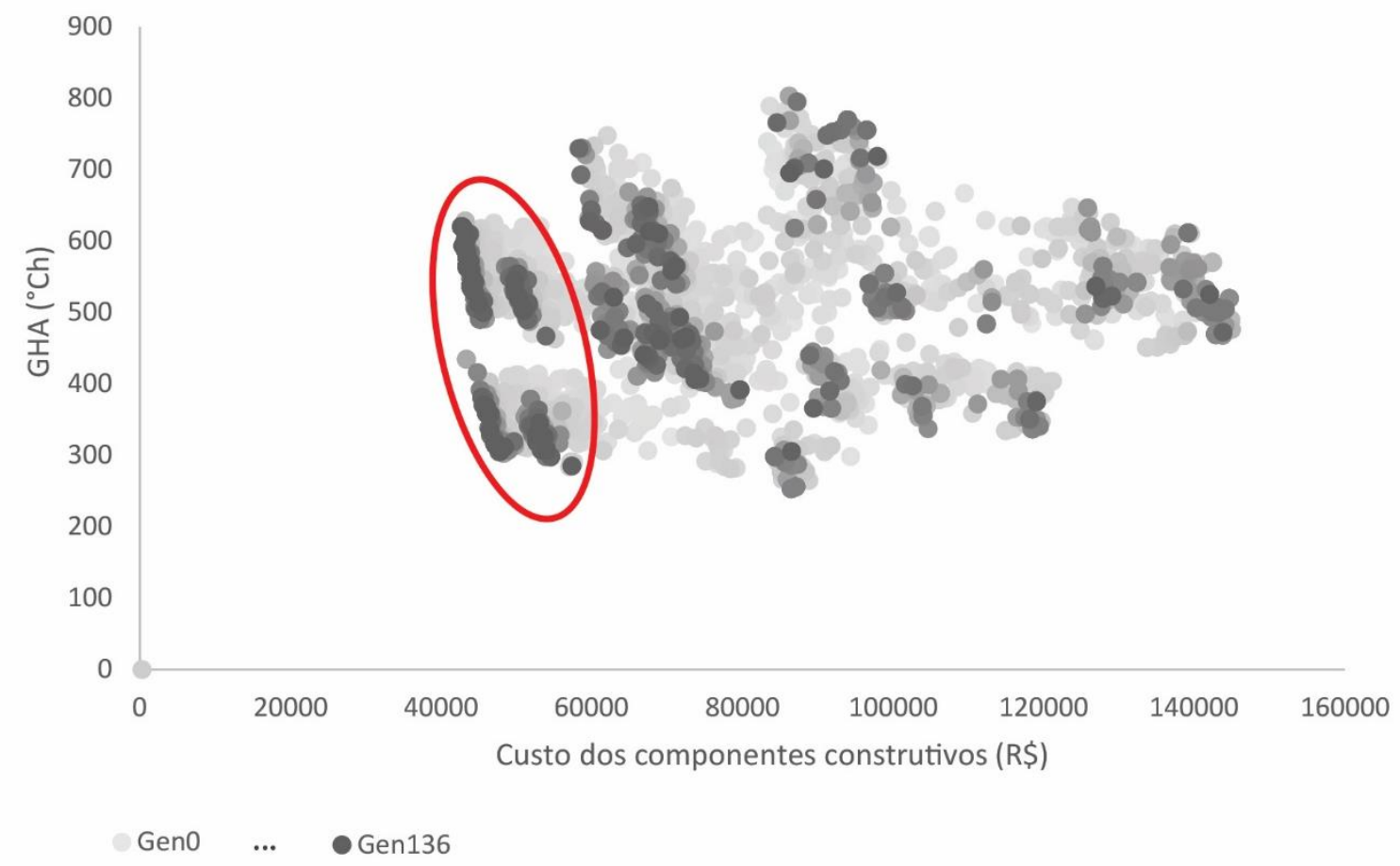

Figura 15 - 10\% das gerações de soluções iniciais (cinza) e 10\% das gerações de soluções finais (vermelho e amarelo) - as soluções em amarelo estiveram presentes nas gerações finais, porém foram descartadas pelos autores das soluções de Pareto (vermelhas)

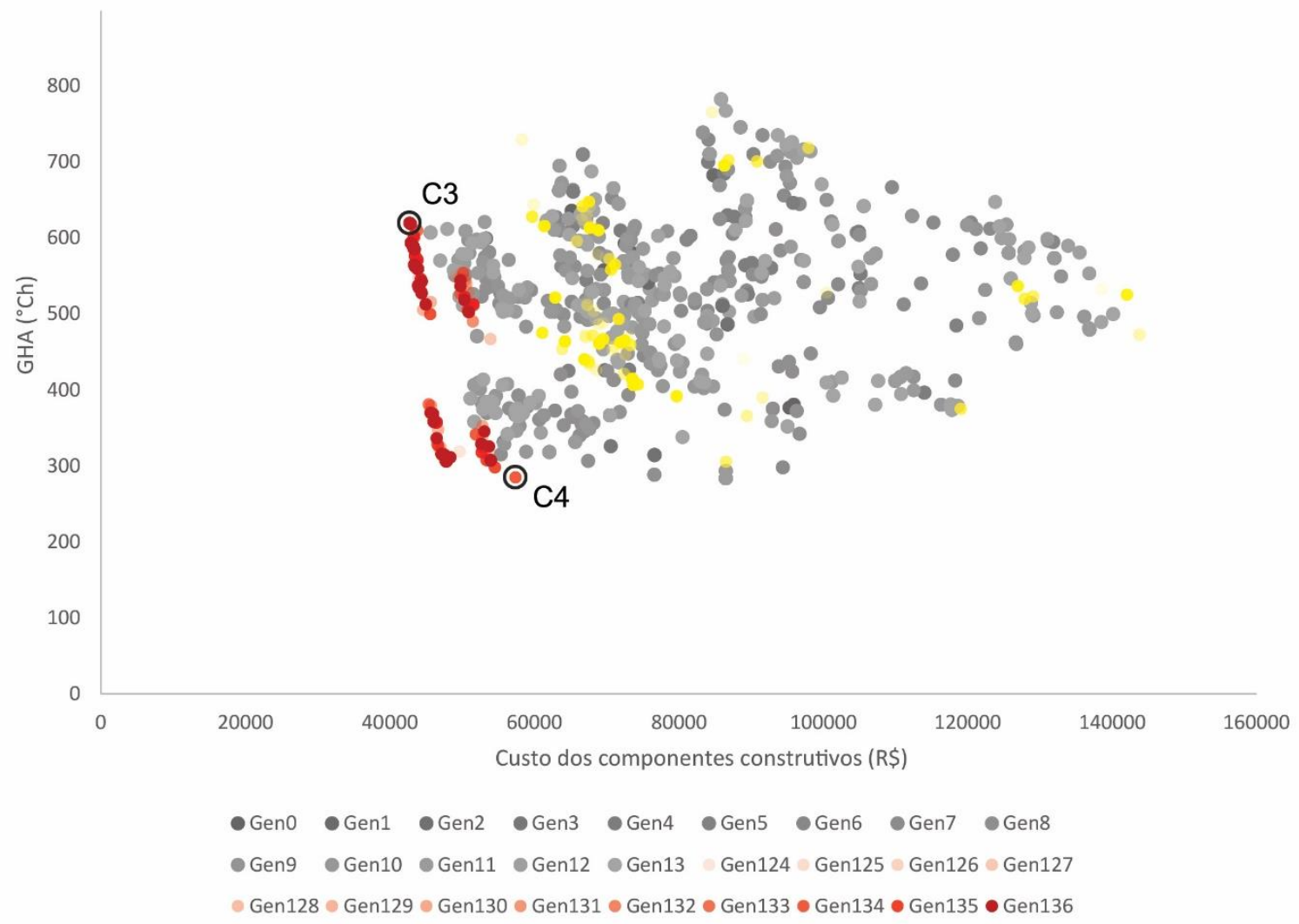


O Caso 3, que apresentou o menor custo dos componentes construtivos, foi idêntico ao Caso 1, apresentado na primeira otimização, e foi identificado com custo de $\mathrm{R} \$ 42.718,06$ e 620,94 ${ }^{\circ} \mathrm{Ch}$ para aquecimento.

O Caso 4, de melhor desempenho térmico entre as soluções de Pareto apresentadas na Figura 14, apresentou $286,09{ }^{\circ} \mathrm{Ch}$ para aquecimento $(5,82 \%$ do intervalo de $\left.550{ }^{\circ} \mathrm{Ch}\right)$ e um custo de $\mathrm{R} \$$ $57.369,64 \quad(14,27 \%$ dos $\mathrm{R} \$ 103$ mil). Os parâmetros que conduziram a este caso são apresentados na Tabela 6 .

Comparado com o caso de melhor desempenho térmico para as condições de verão e inverno, o Caso 4 apresentou parâmetros próximos ao primeiro em relação às dimensões dos ambientes em planta, pé-direito e espessura da laje. Apenas a altura do telhado se diferiu em grande proporção com relação ao Caso 2. Porém, esta se aproximou do Caso de menor $\mathrm{GH}_{\mathrm{Env}}$, com altura do telhado de 2,9 m. Esta solução comprova que, apesar de na primeira otimização ter sido estabelecido um peso maior para o desempenho para verão (64\%) - como indicado pelo RTQ-R (INSTITUTO..., 2012) para a ZB3 - para o caso de Viçosa, os graus-hora de resfriamento tiveram uma contribuição muito pequena para o desempenho geral da envoltória.

Devido à espessura da laje ter se apresentado como um parâmetro com valor otimizado similar para os casos 2 e 4, de melhor desempenho para as duas otimizações, foi realizado um estudo para verificar a influência deste parâmetro isolado sobre o desempenho da envoltória. Os casos de menor e maior GHA entre as soluções de Pareto da segunda otimização foram simulados mantendo-se seus parâmetros constantes, exceto pela espessura da laje, que foi variada entre seu valor mínimo e máximo admissíveis com as restrições estruturais. O caso de menor GHA apresentou $286,09{ }^{\circ} \mathrm{Ch}$ (descrito anteriormente como $\mathrm{C} 4$ e com os parâmetros apresentados na Tabela 6); e o caso de maior GHA apresentou $803,97{ }^{\circ} \mathrm{Ch}$, com seus parâmetros apresentados na Tabela 7 .

Percebe-se que o caso de menor GHA apresentou espessura da laje próxima ao valor máximo admissível $(24 \mathrm{~cm})$, e o caso de maior GHA apresentou espessura de $19 \mathrm{~cm}$ após passar por restrições estruturais (o parâmetro de entrada era 8 $\mathrm{cm}$, porém as restrições admitiram uma espessura mínima aceitável de $19 \mathrm{~cm}$ ). A Tabela 8 indica que para os dois casos investigados ocorreu melhoria no desempenho térmico da envoltória para inverno com o aumento da espessura das lajes.

Esses resultados indicam a contribuição da inércia térmica para a melhoria do desempenho térmico de envoltórias de edificações localizadas na ZB3. De fato, Lamberts et al. (2010) comprovaram por experimentação que a inércia térmica apresenta uma contribuição significativa para a melhoria do desempenho térmico de envoltórias de edificações durante o inverno, quando a ventilação natural é interrompida. No caso da edificação estudada, foi delimitada uma temperatura de setpoint para ventilação natural de $20{ }^{\circ} \mathrm{C}$; ou seja, quando a temperatura interna se encontra abaixo desse valor, a ventilação natural é interrompida, fazendo com que o efeito de inércia térmica contribua de modo positivo para o desempenho da envoltória da edificação (diminuindo os GHAs).

\section{Tabela 6 - Parâmetros para o Caso 4}

\begin{tabular}{l|c}
\hline D1 D2 D3 D4 Eixo X & $2,8 \mathrm{~m}$ \\
Sala D1 D3 Eixo Y & $5,9 \mathrm{~m}$ \\
Escrit D2 D4 Eixo Y & $2,6 \mathrm{~m}$ \\
Sala Escrit Eixo X & $4,1 \mathrm{~m}$ \\
Pé-direito térreo & $3,7 \mathrm{~m}$ \\
Pé-direito 1 pav & $3,6 \mathrm{~m}$ \\
Altura telhado & $3,0 \mathrm{~m}$ \\
Espessura laje & $0,24 \mathrm{~m}$ \\
\hline
\end{tabular}

Tabela 7 - Parâmetros para o Caso de maior GHA

\begin{tabular}{l|l}
\hline D1 D2 D3 D4 Eixo X & $2,5 \mathrm{~m}$ \\
Sala D1 D3 Eixo Y & $4,9 \mathrm{~m}$ \\
Escrit D2 D4 Eixo Y & $6,0 \mathrm{~m}$ \\
Sala Escrit Eixo X & $6,9 \mathrm{~m}$ \\
Pé-direito térreo & $2,8 \mathrm{~m}$ \\
Pé-direito 1 pav & $2,7 \mathrm{~m}$ \\
Altura telhado & $3,0 \mathrm{~m}$ \\
Espessura laje & $0,19 \mathrm{~m}$ \\
\hline
\end{tabular}

284 Fonseca, L. P. G.; Nunes, V. D. L.; Santana, L. O.; Carlo, J. C.; César Júnior, K. M. L. 
Tabela 8 - Resultados para os casos de maior e menor GHA otimizados e com variações na espessura das lajes

\begin{tabular}{l|c|c|c}
\hline & $\begin{array}{c}\text { Espessura do caso } \\
\text { otimizado }\end{array}$ & $\begin{array}{c}\text { Espessura mínima } \\
\text { admitida após } \\
\text { restrições estruturais }\end{array}$ & $\begin{array}{c}\text { Espessura } \\
\text { máxima }\end{array}$ \\
\hline Espessura laje $(\mathrm{cm})$ & \multicolumn{3}{|c}{ Caso menor GHA } \\
\hline GHA $\left({ }^{\circ} \mathrm{Ch}\right)$ & 24 & 11 & 25 \\
\hline Espessura laje $(\mathrm{cm})$ & $\begin{array}{c}\text { Caso maior GHA } \\
\text { (com restrições }\end{array}$ & 19 & 277,49 \\
\hline GHA $\left({ }^{\circ} \mathrm{Ch}\right)$ & 803,97 & 803,97 & 714,84 \\
\hline
\end{tabular}

A otimização baseada em simulação, com a utilização de gráficos em que todas as soluções são plotadas, se mostrou uma ferramenta de grande potencial para a identificação de soluções em que o próprio executor da otimização pode tomar a decisão final sobre qual solução atende de forma mais efetiva a seus objetivos. As Figuras 10 e 15, por exemplo, demonstraram que para as situações criadas é possível encontrar soluções que apresentem diferenças consideráveis em relação ao desempenho térmico em um intervalo de variação de custos pequeno. A combinação dos parâmetros que impactam nos custos e no desempenho térmico da edificação conduziu a soluções mais rápidas e econômicas do que aquelas encontradas em uma análise de sensibilidade, em que o impacto dos parâmetros é avaliado individualmente e que pode não abranger soluções potenciais dentro dos objetivos criados.

\section{Conclusão}

O processo de otimização aplicado apresentou-se como uma estratégia eficaz para a identificação de soluções projetuais formais que atendem aos dois objetivos propostos: encontrar uma volumetria de edificação com um bom desempenho térmico e com custos reduzidos em um universo de condições predeterminadas. Os resultados apresentados como soluções de Pareto indicaram a importância da tomada de decisão do projetista na escolha da solução final, pois no projeto desenvolvido ficou claro que não existe uma proporcionalidade entre o desempenho térmico e os custos da edificação. A combinação de parâmetros da forma permitiu ao motor de otimização selecionar soluções cujas variáveis proporcionavam um desempenho térmico satisfatório sem elevar demasiadamente os custos da edificação após definidos os parâmetros que impactam diretamente no desempenho, tais como materiais, cores e áreas de aberturas.

$\mathrm{Na}$ comparação entre os casos otimizados foram identificados parâmetros da forma (dimensões dos ambientes) cujos valores semelhantes entre os casos de melhor desempenho indicaram as tendências para uma forma eficiente, devido a seu peso na melhoria do desempenho térmico da edificação.

As ferramentas utilizadas, apesar de ainda não serem utilizadas entre projetistas e apresentarem limitações, provaram seu potencial de integração entre o desenvolvimento de projetos e áreas específicas em arquitetura e engenharia, como análise de desempenho. Além disso, por ser uma técnica recente no setor da construção civil, possibilitada pelo desenvolvimento da tecnologia computacional, esta promete um avanço rápido nos próximos anos. Várias das ferramentas computacionais utilizadas encontram-se em fase de aperfeiçoamento, tendo sido atualizadas durante o desenvolvimento desta pesquisa diante de demandas de usuários dos programas e plug-ins utilizados.

No momento, a aplicação do método descrito neste artigo para a etiquetagem de edificações residenciais brasileiras é ainda limitada. Para sua plena aplicação, devem ser realizados aprimoramentos do plug-in Archsim. Além disso, a pesquisa identificou que, apesar de o RTQ-R atribuir um peso maior para as condições de verão para a Zona Bioclimática 3, é necessário maior detalhamento dos climas desta zona para o método de simulação, pois o desconforto durante o inverno foi significativamente maior e, portanto, incompatível com os critérios gerais da ZB3 do método prescritivo. Deve-se alertar que, além da investigação realizada para apenas um clima, a setorização da planta e a orientação dos ambientes foram limitações desta pesquisa, visto que a otimização de arranjos espaciais envolveria novos parâmetros a investigar.

A criação do modelo para otimização também exige um consumo alto de tempo para a modelagem paramétrica; entretanto, os resultados provaram sua eficiência. O número de zonas térmicas e o número de parâmetros impactam 
diretamente no tempo consumido para o alcance da convergência de soluções. Para esse aprimoramento, é necessário o envolvimento de programadores e especialistas em computação, bem como em áreas mais especializadas da matemática. Porém, nesta primeira metade da década de 2010, há um esforço crescente na criação de linguagens de programação mais acessíveis a usuários não especialistas, como o próprio Grasshopper e o Octopus.

Este projeto caracteriza-se, por fim, como um projeto exploratório dos potenciais de aplicação das ferramentas empregadas para a otimização das dimensões dos ambientes de uma edificação residencial, tendo como objetivo o alcance de soluções de desempenho térmico satisfatório e de baixo custo. A inclusão de uma restrição estrutural sobre o modelo também se apresentou de grande importância para a eliminação de soluções inviáveis de projeto, e foi influenciada pelo potencial de inércia térmica da edificação. As perspectivas de avanços sobre esse mesmo projeto são otimistas, pois as ferramentas possibilitam uma integração entre arquitetura e engenharia que deve ser explorada, e as ferramentas empregadas encontram-se em fase de aperfeiçoamento intenso.

\section{Referências}

ANDRADE, M. L. V. X.; RUSCHEL, R. C. BIM: conceitos, cenário das pesquisas publicadas no brasil e tendências. In: SIMPÓSIO BRASILEIRO DE QUALIDADE DO PROJETO NO AMBIENTE CONSTRUÍDO, São Carlos, 2009. Anais... São Carlos, 2009

\section{AMERICAN NATIONAL STANDARDS INSTITUTE; AMERICAN SOCIETY OF HEATING, REFRIGERATING AND AIR- CONDITIONING ENGINEERS. ANSI/ASHRAE 55-2010: thermal environmental conditions for human occupancy. Atlanta, 2010.}

ARO, C.; AMORIM, S. As Inovações Tecnológicas no Processo de Produção dos Sistemas Prediais Hidráulicos e Sanitários. In: CONFERÊNCIA LATINO-AMERICANA DE CONSTRUÇÃO SUSTENTÁVEL, 1.; ENCONTRO NACIONAL DE TECNOLOGIA DO AMBIENTE CONSTRUÍDO, 10., São Paulo, 2004. Anais... São Paulo, 2004.

\section{ASSOCIAÇÃO BRASILEIRA DE NORMAS} TÉCNICAS. NBR 6118: projeto de estruturas de concreto: procedimento. Rio de Janeiro, 2014.

ASSOCIAÇÃO BRASILEIRA DE NORMAS TÉCNICAS. NBR 6120: cargas para o cálculo de estruturas de edificações. Rio de Janeiro, 1980.
ASSOCIAÇÃO BRASILEIRA DE NORMAS TÉCNICAS. NBR 15220: desempenho térmico de edificações. Rio de Janeiro, 2003.

\section{ASSOCIAÇÃO BRASILEIRA DE NORMAS TÉCNICAS. NBR NM 45: agregados: determinação da massa unitária e do volume de vazios. Rio de Janeiro, 2006.}

ATTIA, S. et al. Selection Criteria for Building Performance Simulation Tools: contrasting architects' and engineers' needs. Journal of Building Performance Simulation, v. 5, n. 3, p. 155-169, 2012.

BADER, J.; ZITZLER, E. HypE: an algorithm for fast hypervolume-based many-objective optimization. computer engineering and networks laboratory. Zurich: ETH, 26 nov. 2008. Relatório 286.

\section{CAIXA ECONOMICA FEDERAL; INSTITUTO} BRASILEIRO DE GEOGRAFIA E ESTATÍSTICA. Preço de Insumos em Minas Gerais Desonerado. Relatório de Insumos Agosto de 2015 Desonerado. Relatório. Brasil, 2015. Disponível em:

<http://www.caixa.gov.br/site/paginas/downloads. aspx\#categoria_648>. Acesso em: 2 nov. 2015.

COLORNI, A.; DORIGO, M.; MANIEZZO, V. Genetic Algorithms and Highly Constrained Problems: the time-table case. In: INTERNATIONAL WORKSHOP ON PARALLEL PROBLEM SOLVING FROM NATURE, 1., Dortmund, 1990. Proceedings... Dortmund, 1990.

DOMINGOS, D. Protótipo de Um Sistema de Modelagem Paramétrica de Sólidos. Blumenau, 2002. 73 f. Trabalho de Conclusão de Curso (Curso de Engenharia Civil) - Universidade Regional de Blumenau, Blumenau, 2002.

EVINS, R. A Review of Computational Optimisation Methods Applied to Sustainable Building design. Renewable and Sustainable Energy Reviews, v. 22, p. 230-245, 2013.

FLORIO, W. Modelagem Paramétrica no Processo de Projeto em Arquitetura. In: SIMPÓSIO BRASILEIRO DE QUALIDADE DO PROJETO NO AMBIENTE CONSTRUÍDO, São Carlos, 2009. Anais... São Carlos, 2009

FLORIO, W. Modelagem Paramétrica, Criatividade e Projeto: duas experiências com estudantes de arquitetura. Gestão e Tecnologia de Projetos, v. 6, n. 2, p. 43-66, dez. 2011.

FOOD4RHINO. Octopus. Food4Rhino: apps for Rhino and Grasshopper. Disponível em: <http://www.food4rhino.com/project/octopus?ufh >. Acesso em: 8 jan. 2016.

286 Fonseca, L. P. G.; Nunes, V. D. L.; Santana, L. O.; Carlo, J. C.; César Júnior, K. M. L. 
GIVONI, B. Comfort, Climate Analysis and Building Design Guidelines. Energy and Buildings, v. 18, n. 1, p. 11-23, 1992.

GOSSARD, D.; LARTIGUE, B.; THELLIER, F. Multi-Objective Optimization of a Building Envelope for Thermal Performance Using Genetic Algorithms and Artificial Neural Network. Energy and Buildings, Oxford, v. 67, p. 253-260, 2013.

GUIMARÃES, I. B. B.; CARLO, J. C.

Caracterização Bioclimática da Cidade de ViçosaMG. In: ENCONTRO NACIONAL E VII ENCONTRO LATINO-AMERICANO DE CONFORTO NO AMBIENTE CONSTRUÍDO, 11., Búzios, 2011. Anais... Búzios, 2011.

INSTITUTO NACIONAL DE METROLOGIA, QUALIDADE E TECNOLOGIA. Regulamento Técnico da Qualidade Para o Nível de Eficiência Energética Edificações Residenciais(RTQ-R). Rio de Janeiro: INMETRO, 2012. Portaria n. 18.

LAMBERTS, R. et al. Casa Eficiente: bioclimatologia e desempenho térmico. Florianópolis: UFSC/LabEEE, 2010.

LARTIGUE, B.; LASTERNAS, B.; LOFTNESS, V. Multi-Objective Optimization of Building Envelope for Energy Consumption and Daylight. Indoor and built environment, v. 23, n. 1, p. 7080, fev. 2014.

MAGNIER, L.; HAGHIGHAT, F. Multiobjective Optimization of Building Design Using TRNSYS Simulations, Genetic Algorithm, and Artificial Neural Network. Building and Environment, v. 45, p. 739-746, 2010.

NGUYEN, A. T.; REITER, S.; RIGO, P. A Review on Simulation-Based Optimization Methods Applied to Building Performance Analysis. Applied Energy, Oxford, v. 113, p. 1043-1058, 2014.

ORDENES, M. et al. Metodologia Utilizada na Elaboração da Biblioteca de Materiais e Componentes Construtivos Brasileiros Para Simulações no VisualDoe-3.1. Florianópolis: UFSC, 2003.
PREFEITURA MUNICIPAL DE VIÇOSA. Lei $N^{\circ} \mathbf{1 . 6 3 3}$ de 20 de dezembro de 2004 , que dispõe sobre o Código de Obras e Edificações do Município de Viçosa. Viçosa, 2004. Disponível em: <http://www.netgov.com.br/spm-netphp/doc_pmvicosa/LEGISLACAO/codigo_de_obr as_municipal.pdf?1424713308>. Acesso em: 10 dez. 2015.

SHI, X.; YANG, W. Performance-Driven Architectural Design and Optimization Technique From a Perspective of Architects. Automation in Construction, v. 32, p. 125-135, 2013.

SANTANA, L. O.; GUIMARÃES, I. B. B.; CARLO, J. C. Parametrização Aplicada ao Desempenho Energético de Edificações. V!RUS, São Carlos, v. 11, 2015. Disponível em: <http://www.nomads.usp.br/virus/virus11/?sec=4 \&item=4\&lang=pt $>$. Acesso em: 31 ago. 2016.

SILVA, A. S.; GHISI, E. Análise de Sensibilidade Global dos Parâmetros Termofísicos de Uma Edificação Residencial de Acordo Com o Método de Simulação do RTQ-R. Ambiente Construído, Porto Alegre, v. 13, n. 4, p. 135-148, out./dez. 2013.

SORGATO, M. J. Relatório Técnico da Base de Simulações para o RTQ-R. Florianópolis: UFSC, 2011.

TRESCAK, T.; ESTEVA, M.; RODRIGUES, I. A Shape Grammar Interpreter for Rectilinear Forms. Computer-aided Design, v. 44, n. 7, p. 657-670, jul. 2012.

VASCONCELOS, T. B.; BORDA, A. A. S.; VECCHIA, L. F. D. A Parametrização Como Experiência Prévia Para a Estruturação de Métodos Projetuais em Arquitetura. SIGRADI, v. 1, n. 8, p. 297-301, dez. 2014.

ZITZLER, E.; LAUMANNS, M.; THIELE, L. SPEA-2: improving the strength pareto evolutionary algorithm. Computer Engineering and Networks Laboratory. Zurich: ETH, 2001. Relatório 103.

\section{Agradecimentos}

Os autores agradecem à Fapemig e ao $\mathrm{CNPq}$ pelo suporte e financiamento da pesquisa. 


\begin{abstract}
Ligiana Pricila Guimarães Fonseca
Departamento de Arquitetura e Urbanismo | Universidade Federal de Viçosa | Av. P.H.Rofls, s/n, Centro | Viçosa - MG - Brasil | CEP 36570-000 | Tel.: (31) 3899-1966 | E-mail: ligiana.fonseca@gmail.com
\end{abstract}

Vitor Dias Lopes Nunes

Departamento de Engenharia Civil, Centro de Ciências Exatas e Tecnológicas | Universidade Federal de Viçosa | Tel.: (31) 3899-2758 | E-mail: vitor.nunes@ufv.br

\title{
Laila Oliveira Santana
}

Departamento de Arquitetura e Urbanismo | Universidade Federal de Viçosa | Tel.: (31) 3899-1966 | E-mail: lailaufv@gmail.com

\section{Joyce Correna Carlo}

Departamento de Arquitetura e Urbanismo | Universidade Federal de Viçosa | Tel.: (31) 3899-1982 | E-mail: correnacarlo@gmail.com

\section{Kléos Magalhães Lenz César Júnior}

Departamento de Engenharia Civil, Centro de Ciências Exatas e Tecnológicas | Universidade Federal de Viçosa | Tel.: (31) 3899-1484 |

E-mail: kleos@ufv.br

\section{Revista Ambiente Construído}

Associação Nacional de Tecnologia do Ambiente Construído

Av. Osvaldo Aranha, $99-3^{\circ}$ andar, Centro

Porto Alegre - RS - Brasil

CEP $90035-190$

Telefone: +55 (51) 3308-4084

Fax: +55 (51) 3308-4054

www.seer.ufrgs.br/ambienteconstruido

E-mail: ambienteconstruido@ufrgs.br 